\title{
Tornado, Maximum Wind Gust, and Extreme Rainfall Event Recurrence Frequencies at the Savannah River Site
}

by

A. H. Weber

Westinghouse Savannah River Company

Savannah River Site

Aiken, South Carolina 29808

DOE Contract No. DE-AC09-96SR18500

This paper was prepared in connection with work done under the above contract number with the U.S.

Department of Energy. By acceptance of this paper, the publisher and/or recipient acknowledges the U. S. Government's right to retain a nonexclusive, royalty-free license in and to any copyright covering this paper, along with the right to reproduce and to authorize others to reproduce all or part of the copyrighted paper. 
WSRC-TR-98-00329

\section{Tornado, Maximum Wind Gust, and Extreme Rainfall Event Recurrence Frequencies at the Savannah River Site(U)}




\section{DISCLAIMER}

This report was prepared as an account of work sponsored by an agency of the United States Government. Neither the United States Government nor any agency thereof, nor any of their employees, makes any warranty, express or implied, or assumes any legal liability or responsibility for the accuracy, completeness, or usefulness of any information, apparatus, product, or process disclosed, or represents that its use would not infringe privately owned rights. Reference herein to any specific commercial product, process, or service by trade name, trademark, manufacturer, or otherwise does not necessarily constitute or imply its endorsement, recommendation, or favoring by the United States Government or any agency thereof. The views and opinions of authors expressed herein do not necessarily state or reflect those of the United States Government or any agency thereof.

This report has been reproduced directly from the best available copy.

Available to DOE and DOE contractors from the Office of Scientific and Technical Information, P.O. Box 62, Oak Ridge, TN 37831; prices available from (615) 576-8401.

Available to the public from the National Technical Information Service, U.S. Department of Commerce, 5285 Port Royal Road, Springfield, VA 22161. 


\section{DISCLAIMER}

\section{Portions of this document may be illegible in electronic image products. Images are produced from the best available original document.}


WSRC-TR-98-00329

September 1998

\section{Tornado, Maximum Wind Gust, and Extreme Rainfall Event Recurrence Frequencies at the Savannah River Site(U)}

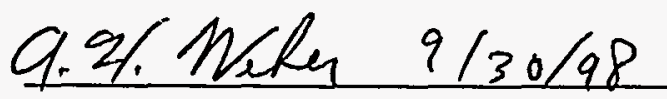

A. H. Weber, Author, MTD/NTS

Westinghouse Savannah River Company

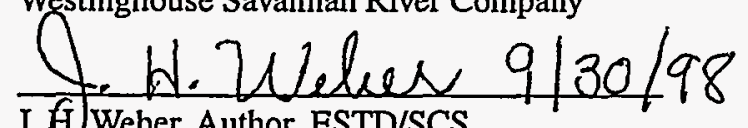

J. f. Weber, Author, ESTD/SCS

Westinghouse Savannah River Company

M. J. Parker, Author, MTD/NTS

Westinghouse Savapnah River Company

C.14./4t 9/30/98

C. H. Hunter, Author, MTD/NTS

Westinghouse Savannah River Company

MOMnyan 10/3/98

C. O. Minyard, Author, MTD/NTS

Westipghouse Savgnah River Company

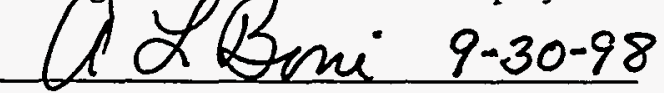

A. L. Boni, Manager, NTS

Westipghouse Savannah River Company

$$
\text { K. P. Addin } 9.30 .98
$$

R. P. Addis, Responsible Manager, MTD/NTS

Westinghouse Savannah River Company

E. P. Shine 9/30198

G. P. Shine, Technical Réviewer, ESTD/SCS

Westinghouse Savannah River Company

Prepared for the U.S. Department of Energy under contract no. DE-AC09-89SR18035 


\title{
Contents
}

\author{
Executive Summary 1 \\ Introduction 3 \\ Tornadoes 5 \\ Databases 5 \\ Tornadoes at the Savannah River Site 5 \\ Database for Tornado Frequency and Intensity 7 \\ Database for Damage Path Area versus Tornado Intensity 9 \\ Summary of Database Used 9 \\ Model 10 \\ Formulation of the Tornado Hazard Probability Model 10 \\ Estimation of Average or Expected Damage Area 12 \\ Log-Linear Regression to Predict the Average Damage \\ Area per F-Scale Tornado 12 \\ Non-Rated and Unreported Tornadoes 13 \\ Misclassification Errors 13 \\ Intensity Variations within the Damage Path 14 \\ Results for Tornadoes 14 \\ Wind Gusts 16 \\ Wind Gust Data 16 \\ Model 17 \\ Summary of Tornadic Wind and Wind Gusts 19

\section{Extreme Rainfall 19} \\ Databases 19 \\ Model 22 \\ Results for Extreme Rainfall 28

\section{Acknowledgments 31} \\ References 31 \\ Appendices A-1
}




\section{List of Figures}

Figure 1. Tornadoes Over the Southeast (F-Scales 0 to 5) and Alabama (F-Scales 3 to 5) 11

Figure 2. Maximum Wind Speed (Three-Second Gusts) for Tornadic Wind and Wind Gusts 20

Figure 3. Rain Gauge Locations 23

Figure 4. Rainfall Recurrences by Accumulation Periods 30

\section{List of Tables}

Table I. Examples of the Differences Between the SPC's "Official" and "Unofficial" Databases 6

Table II. Documented Tornadoes at SRS 6

Table III. Relationships Between the Fujita Scale and Wind Gust Speeds (after McDonald, 1997) 7

Table IV. $\quad$ Expected and Observed Tornadoes by Area Centered at SRS 8

Table V. Occurrence-Intensity Distribution for the Two-Degree Square Centered at $33.25^{\circ} \mathrm{N} 81.63^{\circ} \mathrm{W}$ from 1967 through 199614

Table VI. Intensity-Occurrence Distribution Adjusted for Misclassification 14

Table VII. Predicted and Observed Average Areas per F-Class Tornado 15

Table VIII. Area by F-Scale Tornado after Adjusting for Misclassification and Path Area Variation 15

Table IX. $\quad$ Probabilities for Three-Second Tornadic Wind Speeds

(Minimum Value F-Class Wind Speed) 16

Table X. Wind Gust Data Source 16

Table XI. Means, Standard Deviations, and Coefficient of Variation by Station 17

Table XII. Tornadic Wind Speeds (Three-Second Gusts) with Return Period and Probability 19

Table XIII. Wind Gusts (Three-Second Gusts) with Return Period and Probability 19

Table XIV. $\quad$ Stations with Daily Precipitation Data 21

Table XV. $\quad$ Stations with Hourly Precipitation Data 21

Table XVI. Multiplication Factors for Yearly Maximum by Rainfall Periods 22

Table XVII. Station Average, Standard Deviation, and Coefficient of Variation for Maximum

Yearly Rainfall by Rainfall Periods $\mathbf{2 4}$

Table XVIII. Scale and Location Parameters for Type II GEV by Rainfall Periods 27

Table XIX. Extreme Rainfall Estimates by Accumulation Period 29

\section{List of Appendices}

Appendix I. Tornado Database A-1

Appendix II. Breakdown of Tornado Data A-11

Appendix III. Frequency of Tornadoes with F-Scales (0 to 5) for the Georgia-South Carolina Region A-13

Appendix IV. Frequency of Occurrences for Tornadoes by 22.5 Degree Sector and F-Scale Classes A-15 


\section{Executive Summary}

This report explains the data sources and the methods used for determining probabilistic hazard curves for tornadic winds, wind gusts, and extreme rainfall events for the Savannah River Site (SRS). Probabilistic hazard curves are used to help determine design requirements for onsite structures for hazard analyses.

The tornado data for this study were obtained from NOAA's Storm Prediction Center in Norman, Oklahoma, and from tornado investigations carried out by the Atmospheric Technologies Group (ATG) at the Savannah River Site. The model used to determine tornado risk probabilities is based on work done by J. R. McDonald and D. Lu (1995).
The wind gust data were obtained from the National Climatic Data Center (NCDC) records and from computer data archives maintained by the Atmospheric Technologies Group (ATG). The extreme value distribution used for the wind gusts and extreme rainfall is based on the Fisher and Tippett (1928) formulation and the parameter estimation for fitting the distributions was done using the methods of J. Eliasson (1997) and J. R. M. Hosking, et al. (1985).

Results for the extreme value statistics are presented in both tabular and graphical form. 
$\because:$

Tornado, Maximum Wind Gust, and Extreme Rainfall Event

Recurrence Frequencies at the Savannah River Site 


\section{Introduction}

DOE Order 420.1, Facility Safety, outlines the requirements for Natural Phenomena Hazards (NPH) mitigation for new and existing DOE facilities. Specifically, NPH include tornadic winds, maximum wind gusts, and extreme rainfall events. Probabilistic hazard curves for each phenomenon indicate the recurrence frequency, and these hazard curves must be updated at least every 10 years to account for recent data, improved methodologies, or criteria changes. Pre- vious studies for SRS by McDonald (1985 and 1997) and Fujita (1980) have been used to comply with Order 420.1 with respect to NPH mitigation. In 1997, the Structural Mechanics Department requested that the Atmospheric Technologies Group (ATG) update probabilistic hazard curves for tornadic winds, maximum wind gusts, and extreme rainfall events for the SRS. The primary deliverable is this report, which includes the aforementioned curves, descriptions, and verifications. Calculations are included in a separate calculation note (Weber, 1998). 


\section{Tornadoes}

\section{Databases}

The tornado databases for this project were problematic, not because there was insufficient data, but because there is no undisputed, official source of data. Instead of a single, official source of data, there are a few "semiofficial" sources of data that, unfortunately, differ substantially from one another. As the existence and nature of the different data sets were uncovered, the computer codes had to be revised to accommodate changes in the data format.

Initially the tornado data for this project was obtained through a request to the Director of the Storms Prediction Center (SPC), in Norman, Oklahoma. Data for a region bounded by $30.5^{\circ} \mathrm{N}, 77.5^{\circ} \mathrm{W}$ and $35.5^{\circ} \mathrm{N}, 84.5^{\circ} \mathrm{W}$ (covering the states of South Carolina, Georgia, parts of North Carolina, Alabama, and Florida) was requested and subsequently received via FTP over the internet. The tornado data abstracted from this initial data source was a small fraction of the total data set, which consisted of tornadoes, waterspouts, and hail-containing thunderstorms within the requested region. Since the data had originated at the SPC and the data were slated to become the SPC's primary database, this data set was referred to as the "official" database.

SPC's "official" dataset was compared to a tornado dataset from the Southeast Regional Climate Center (Purvis, et al., 1990). Purvis assembled this database while performing work as the State Climatologist for South Carolina. Upon examination it became apparent that there were a significant number of differences between the official database and the State Climatologist's database. The main differences were that tornadoes appeared in the State Climatologist's database that were not contained in the Storm Prediction Center's official database.

Shortly after these data discrepancies were discovered, a second tornado database was located on the Storm Prediction Center's web site. This web-posted database was called the "unofficial" database to differentiate it from the earlier official SPC database. This database was downloaded, transferred to the SRTC1 computer, and compared to the other databases. The database compiled by Purvis and a similar database prepared by the Georgia State Climatologist (Plummer, 1991) were apparently taken from the same source as the web-posted, unofficial database since all tornadoes could be matched when compared.
Further investigation showed a large fraction of the tornadoes in the unofficial database were not contained in the Storm Prediction Center's official database. After studying the unrecorded tornado entries in the official database, it was found that the unrecorded entries were missing lift-off points, i.e., tornadoes were not included in the official database whenever their lift-off point was missing. An example is shown in Table I. Lines 4-8 show no entry in the official database whereas lines 13-17 from the unofficial database show 5 tornadoes missing their lift-off latitude and longitude.

Another difference in the databases was that tornado path segments from the same storm were combined into a single entry in the official database. For example, the storm listed in Table I, line 10 (from the official database), is a composite of three separate segments in the unofficial database (see lines 19-21).

Tornado data entries without a lift-off point are just as valid as are those with complete data entries. (In the aftermath of a tornado, if a National Weather Service (NWS) investigator was not able to determine the lift-off point, none was reported.) It was decided to adopt the SPC web-page database since the number of tornado occurrences are more accurately reflected in the data. To improve the format and comparability of the database, all tornado segments of a given tornado path were combined into a single entry whenever these were easy to identify. This also aided in determining an accurate damage path length for a given storm.

\section{Tornadoes at the Savannah River Site}

Nine tornadoes are known to have occurred at the Savannah River Site since its inception-Pepper and Schubert (1978), Garrett (1983), Parker and Kurzeja (1990), and Parker (1991). All nine have been formally documented by the Atmospheric Technologies Group (or its predecessors) four of which were found in the "unofficial" database. The additional tornadoes from SRS investigations were entered into the database to make it complete. Each of the documented tornadoes is described in Table II.

The most damaging tornado occurred on October 1, 1989, over the southern part of the SRS. Major damage to forested areas was observed. Most of the damage from the other tornadoes was relatively minor; although, in most cases, merchantable timber was harvested as a result of tree losses. No significant site building damage has been observed due to any of the nine tornadoes at the SRS. 
Table I. Examples of the Differences Between the SPC's "Official" and "Unofficial" Databases

\begin{tabular}{|c|c|c|c|c|c|c|c|c|}
\hline 1 Date & Time & $\begin{array}{l}\text { Starting } \\
\text { Latitude }\end{array}$ & $\begin{array}{l}\text { Starting } \\
\text { Longitude }\end{array}$ & $\begin{array}{l}\text { Lift-off } \\
\text { Latitude }\end{array}$ & $\begin{array}{l}\text { Lift-off } \\
\text { Longitude }\end{array}$ & Length & Width & F-Scale \\
\hline 2 & EST & dec, degrees & dec. degrees & dec. dègrees & dec degrees & miles & $\overline{f t}$ & \\
\hline 3 Official & & & & & & & & \\
\hline 4 No entry & & & & & & & & \\
\hline 5 No entry & & & & & & & & \\
\hline 6 No entry & & & & & & & & \\
\hline 7 No entry & & & & & & & & \\
\hline 8 No entry & & & & & & & & \\
\hline \multicolumn{9}{|l|}{9} \\
\hline $1023-$ Apr-83 & $20: 19$ & 33,17 & 81.45 & 33.33 & 80.87 & 33 & 600 & 3 \\
\hline \multicolumn{9}{|l|}{11} \\
\hline \multicolumn{9}{|l|}{12 Unofficial } \\
\hline 13 5-Apr-57 & $20: 30$ & 34.70 & 80.78 & No entry & No entry & 1 & 100 & 1 \\
\hline $148-A p r-74$ & $16: 33$ & 34.42 & 82.75 & No entry & No entry & 1 & 300 & $\frac{1}{3}$ \\
\hline $\begin{array}{ll}15 & 16 \text {-Aug- } 94 \\
\end{array}$ & $11: 00$ & 33.88 & 81,33 & No entry & No entry & 0.1 & 150 & 2 \\
\hline \begin{tabular}{|l|l|}
16 -Aug-94 \\
\end{tabular} & $12: 35$ & 33.92 & 81.25 & No entry & No entry & 0.3 & 220 & $\overline{3}$ \\
\hline 17 7-Noy-95 & $16: 38$ & 3420 & 79.70 & No entry & No entry & 0.5 & 120 & 2 \\
\hline \multicolumn{9}{|l|}{18} \\
\hline 19 23-Apr-83 & $20: 20$ & 33.17 & 81.45 & 33.23 & 81.22 & 13 & 600 & 3 \\
\hline 20 23-Apr-83 & $20: 46$ & 33.23 & 81.22 & 33.32 & 80.93 & 16 & 600 & 3 \\
\hline $2123-A p r-83$ & $21: 18$ & 33,32 & 80.93 & 33,33 & 80.87 & 4 & 600 & 3 \\
\hline
\end{tabular}

Table II. Documented Tornadoes at SRS

\begin{tabular}{|c|c|c|c|c|c|c|}
\hline DaterTime (local) & Location & Path & Width & Length & F-Scale & Conuties \\
\hline $\begin{array}{l}\text { May } 28,1976 \\
1530 \\
\end{array}$ & Central Shops to F Area & 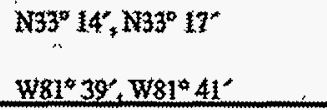 & $300 \mathrm{ft}$ & 5 miles & Fi & $\begin{array}{l}\text { Bamuell, } \\
\text { Aikent }\end{array}$ \\
\hline $\begin{array}{l}\text { May 28, } 2976 \\
2043\end{array}$ & near Road 8 and Road 8-1 & $\begin{array}{l}N 33^{\circ} 20^{\circ} * 133^{\circ} 20^{\circ} \\
W 81^{\circ} 31^{\circ}+181^{\circ} 32^{\circ}\end{array}$ & $\$ 00 \mathrm{ft}$ & 0.5 mite & $\mathbf{F} 1$ & Batntect \\
\hline July 2,1976 & $\begin{array}{l}\text { near A Area to old SR- } \\
\text { Ecology Lato }\end{array}$ & $\begin{array}{c}N 33^{\circ} 19^{\circ}, N^{\prime} 33^{*} 22^{\prime} \\
W 81^{\circ} 46^{\circ}, W 81^{\circ} 39^{\prime}\end{array}$ & 300 At (est) & $7.5 \mathrm{mi}(\mathrm{est})$ & $\mathrm{FI}$ & Aiken \\
\hline $\begin{array}{l}\text { Aprit } 23,983 \\
2015\end{array}$ & Jackson to near A Area & $\begin{array}{l}N 33^{\circ} 20^{\circ}+N 33^{\circ} 21^{\prime} \\
W 81^{\circ} 48^{\circ}, W 81^{\circ} 42^{\circ}\end{array}$ & 30010 & 6.0 milles & FI & Aiken \\
\hline $\begin{array}{l}\text { Oclober } 1 ; 1989 \\
1930\end{array}$ & $\begin{array}{l}\text { latge swath over the } \\
\text { sputhera } \\
\text { part of the SRS from the } \\
\text { Savannali Riyer to offsite } \\
\text { near Snelling, } \$ C\end{array}$ & $\begin{array}{l}\cdots \\
N 33^{\circ} 6, N^{n} 13^{\infty} \\
W 81^{\circ} 40^{\circ}, W 81^{\circ} 27^{*}\end{array}$ & 10 mite & 16 miles & $\bar{n}_{\%}$ & Bamswell \\
\hline $\begin{array}{l}\text { Mandh } 1,1991 \\
2215:\end{array}$ & south of SRFS & $\begin{array}{l}N 33^{\circ} 21^{*} 15^{*}, N 33^{*} 21^{*}, 56^{*} \\
W 81^{\circ} 40^{\circ} 54^{\prime}, W 81^{\circ} 40^{\prime} 29^{\prime}\end{array}$ & $450 \mathrm{ft}$ & 1,0 mile & W & Aiken \\
\hline $\begin{array}{l}\text { Marct } 3 \times 1991 \\
1500 \\
\end{array}$ & $\begin{array}{l}\text { north of } Z \text { Anea } \\
\text { northeastward fowaro }\end{array}$ & $\begin{array}{l}N 33^{\circ} 18^{\circ}, N_{33^{\circ}} 23^{\circ} \\
\text { W } 81^{\circ} 38^{\circ}, W 81^{\circ}, 34^{\circ} \\
\text { US } 278\end{array}$ & $600 \mathrm{ft}$ & 7.5 miles & $\mathbf{F 2}$ & Aiken \\
\hline 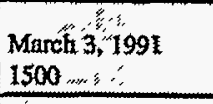 & $\begin{array}{l}\text { north of F Area North } \\
\text { casturand toward US } 278\end{array}$ & $\begin{array}{l}\mathrm{NB3}^{\circ} 58^{\circ}+\mathrm{N33}^{\circ} 23^{\circ} \\
\mathrm{W} 81^{\circ} 40^{\circ} \mathrm{Wg} 1^{\circ} 35^{\circ}\end{array}$ & $\begin{array}{r}600 \mathrm{ft} \\
\end{array}$ & 7.5 miles & (2) & Aiken \\
\hline $\begin{array}{l}\text { March 29, } 1991 \\
1415 \text { dis, } \\
n=\end{array}$ & $\begin{array}{l}\text { SC } 125 \text { just torth } \\
\text { of D Aret }\end{array}$ & 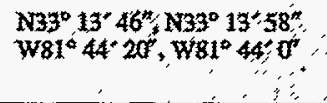 & $450 \mathrm{ft}$ & 0.5 milie & 22 & Aiken \\
\hline
\end{tabular}


Four of the SRS tornadoes cited above were not part of the database supplied by the SPC. These tornadoes occurred on May 28 (2043 local time), 1976; July 2, 1976; March 1, 1991; and March 29, 1991. The path coordinates for the May 28 (1530), 1976; March 3 (both storms), 1991; and October 1, 1989 tornadoes were adjusted from the Severe Storms Laboratory listing to more accurately reflect the path coordinates documented in the references in Table II.

The SPC's "unofficial" database with additional SRS tornadoes as described above was felt to be the one most appropriate to use for SRS in this study.

\section{Database for Tornado Frequency and Intensity}

Tornado intensity is conveniently measured by the F-scale which is based on a damage assessment system devised by Fujita $(1971,1973)$. The F-scale definitions are related to tornadic wind gust speeds as shown in Table III below.

A one-degree square centered on the site of concern was recommended by $\mathrm{Lu}$ (1995) to create a suitable database for a tornado touchdown frequency and intensity analysis. However, other geographical regions have been recommended and used in tornado risk studies. In order to determine the appropriate region for estimating the tornado risk to SRS, consideration was given to geographical homogeneity with respect to tornado formation and occurrence around the SRS. Increasingly larger area concentric squares were statistically compared to determine if the tornado touchdown occurrence was equivalent for each non-overlapping region segment.

The smallest region considered was a one-degree square centered at SRS. Since there were no occurrences of F-4 or F-5 tornadoes and very few F-3 tornadoes within this onedegree square, a two-degree square was also considered. The two-degree square was divided into two disjoint areas, and the tornado frequency was compared based on the assumption that a given tornado would be equally likely to touchdown anywhere within the two-degree square. Tornadoes were counted that (1) either touched down or lifted off within the one-degree square or (2) outside the one-degree square but within the two-degree square. The effective area for the one-degree square was $3,971.37 \mathrm{sq}$. mi. The effective area for the two-degree square was $15,588.85 \mathrm{sq}$. mi. The area outside the one degree square but within the two square was $11,617.48 \mathrm{sq}$. mi. Assuming the number of expected tornadoes within each of the two non-overlapping areas is proportional to the region's area, a chi square test was used as a test statistic to determine if the observed occurrences came from the same population.

In addition to comparing the one-degree and two-degree squares for equality of tornado occurrence, time periods over the 1951 through 1996 range were compared. Because of improvements in reporting and identifying tornado occurrences, there is the chance that the tornadoes reported in the database will increase over time. (This does not violate the assumption that the true tornado occurrence remains the same throughout the time period but is a test of the reporting of tornado occurrences.) The occurrence frequency for earlier time periods was compared with the frequency for later time periods under the assumption of constant occurrence over the entire time period using a chi-square test statistic. Several different time periods were considered but these were ultimately reduced to two: 1951-1966 and 1967. 1996.

Table IV gives the number of tornadoes by F-scale for each of the two time periods and the two areas being compared. There are two hypotheses to be considered. The first assumes the frequency of tornado touchdown occurrence is the same for a two-degree square as for a one-degree square assuming the tornado occurrence is proportional to area. The second hypothesis assumes the reporting and occurrence rate per year of tornado touchdowns within the chosen area is the same for the two time periods. It is not possible to separate the reporting and occurrence rate since only the reported tornado occurrences for previous years are available.

Table III. Relationships Between the Fujita Scale and Wind Gust Speeds (after McDonald, 1997). Note: A three-second gust is considered to be identical to an instantaneous 1.5 second sampled gust.

\begin{tabular}{|c|c|c|c|c|c|c|}
\hline Fujita Scale & Fo & F1 & F2 & F3 & F4 & F5 \\
\hline $\begin{array}{l}\text { Fastest } 1 / 4 \text { mile } \\
\text { (mph) }\end{array}$ & $\begin{array}{c}40-72 \\
\therefore\end{array}$ & $73-112$ & 113-157 & $158-206$ & $207-260$ & $261-318$ \\
\hline $\begin{array}{c}\text { 3-Second gust } \\
\text { (mph) }\end{array}$ & $45-78$ & $79-117$ & $118-161$ & $162-209$ & $210-261^{3}$ & $262-318$ \\
\hline
\end{tabular}


Table IV. Expected and Observed Tornadoes by Area Centered at SRS

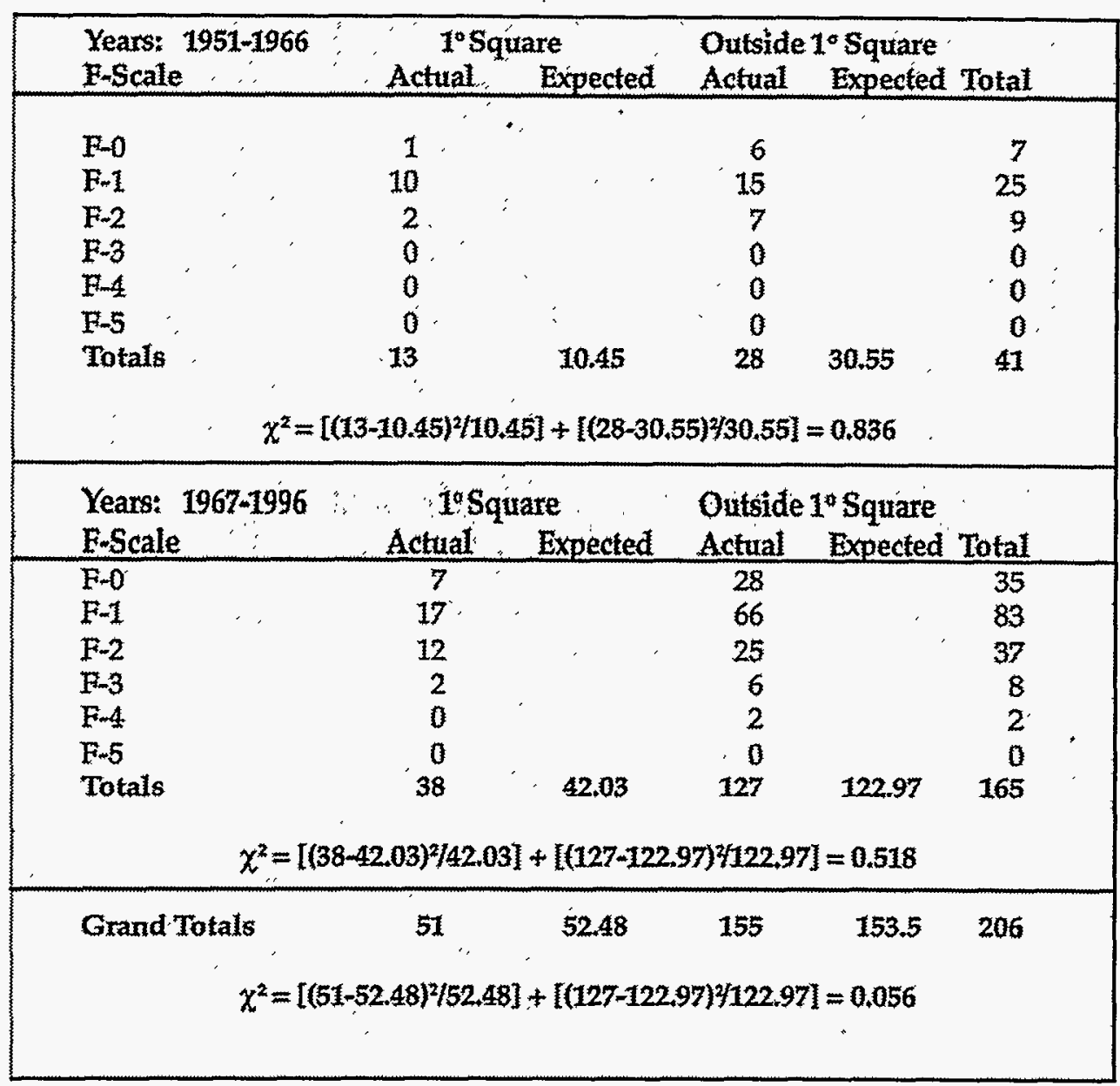

The chi-square test statistic was used to determine if the two hypothesis were likely to be true given the number of tornado occurrences observed and recorded on the database. Non-overlapping areas were needed for a valid test of the null hypothesis. If the tornado touchdown occurrence rate can be considered equal for these two regions, then the expected occurrence rate is assumed proportional to the area (or number of years): Furthermore, the assumption is made that the tornado occurrence rate is uniform over the entire region of concern.

The test statistic is given in Eq. (1). The chi-square sum is then compared with the 95th percentile of the chi-square distribution with 1 degree of freedom since two groups are being compared for both region and time period.

$\chi^{2}=\Sigma$ (observed - expected) $)^{2} /$ expected

The test could be done within region and time period. However, the decision was a two-step process. First, a test of the two regions was done. Then within the selected region, a test of the two time periods was done. As an additional check, the chi-square test was applied separately to the two time periods for the two regions.

A total of 206 tornadoes was observed within the two-degree square. Fifty-one tornadoes were within the one-degree square and the remaining 155 were outside the onedegree square but within the two-degree square. The expected number of tornadoes within each of these two areas is:

$$
\begin{gathered}
\text { Expected number within } 1^{\circ}= \\
(206)(3971.37) /(15,588.85)=52.48 \\
\text { Expected number within } \\
2^{\circ}-1^{\circ}=(206)(11,617.48) /(15,588.85)=153.52 .
\end{gathered}
$$

The chi-square statistic is listed in Table IV. For the two areas, the chi-square sum was 0.056 . The 95 th percentile for 1 degree of freedom is 3.84. Thus, there is no significant difference between a one-degree square and a twodegree square in the tornado frequency occurrence rate. 
For the comparison of the two time periods within the twodegree square, 41 tornadoes occurred in the 16 years between 1951 and 1966, and 165 occurred in the 30 years between 1967 and 1996. The expected number for each group is given by

$$
\begin{gathered}
\text { Expected number }(1951-1966)= \\
(206)(16 / 46)=71.65 \text { and } \\
\text { Expected number }(1967-1996)= \\
(206)(30 / 46)=134.35 .
\end{gathered}
$$

The chi-square statistic for the time period comparison is

$\chi^{2}=\left[(165-134.35)^{2 / 134.35]}+\left[(41-71.65)^{2 / 71.65]}\right]=20.10\right.$,

which exceeds the 95th percentile for the chi-square distribution with 1 degree of freedom. Thus, there is a significant difference in the reported tomado frequency rate for these two time periods. If the tornado frequency is determined from all 46 years, the estimate will be too low. Only those tornado occurrences between 1967 and 1996 should be used to determine the tornado frequency. The same two-degree square region and 1967-1996 time period was used to estimate the tornado intensity distribution. However, all tornado occurrences within the two-degree square over the both time periods were used in the process to estimate the tornado damage path area by intensity distribution.

After determining that there was a difference in occurrence rate between the two time periods, a second chi-square test was done to compare the two separate regions within each time period. The concern was that there could be a difference in region due to time periods that might be confounded with time. The frequency rate of occurrence by area was not significantly different for each of the two time periods.

\section{Database for Damage Path Area versus Tornado Intensity}

In order to determine the damage path area versus tornado intensity distribution and to avoid extrapolation, data for all tornado intensity classes were needed. Because there were no F- 5 tornadoes and few F-4 and F-3 tornadoes within the two-degree square used for tornado frequency, the database needed to be expanded to include additional F-3, F-4, and F-5 tornadoes. The tornadoes used to estimate the area by intensity distribution should be similar to the damage area expected at SRS given a tornado of a specific intensity were to occur. The relationship between the damage path and the tornado intensity (F-scale) is not necessarily limited to the same region used for the tornado occurrence. In the $\mathrm{Lu}$
(1995) model the entire United States region east of the Rocky Mountains was used to model the predicted width of a tornado path given the observed length and F-scale.

It is extremely important in predicting the average damage path for each F-scale category tornado to have a sufficient number of tornadoes. With a void of tornadoes in the higher F-scales, the regression equation will be extrapolating outside the data region. It is also important that the region used to estimate the damage path versus F-scale be similar with respect to the damage area. Unless a weighted linear regression relationship is used to model the area versus the intensity, the damage path area variability should be approximately the same across the six F-scale category tornadoes.

Since there were no F-5 scale tornadoes in the two-degree square and only two F-4 scale tornadoes, additional tornadoes of the higher intensities needed to be added to the database to determine the damage path area by intensity distribution. The following set of tornado damage path areas were used:

- All tornadoes within the two-degree square over both time periods,

- All F-3 tornadoes occurring in the states of Georgia and South Carolina over both time periods, and

- All F-4 and F-5 tornadoes occurring in the states of Georgia, South Carolina, and Alabama over both time periods.

Alabama was chosen over North Carolina or Florida because of the state's similar climatology, and the fact that frontal systems usually approach South Carolina from the west rather than from the south or north. This does not change the tornado occurrence probabilities but enhances the reliability of the damage area-intensity relationship. The tornadoes used for the damage area relationship are listed in Appendix I. The tornadoes for the frequency and intensity are a subset of these are indicated as such in the Appendix.

\section{Summary of Database Used}

The final database used for the risk probability determination was a two-degree square centered at the Savannah River Site $\left(33.25^{\circ} \mathrm{N} 81.63^{\circ} \mathrm{W}\right)$ in which the tornado frequency and the intensity frequency distributions were determined using only the tornado data from 1967 through 1996. A larger database was used to determine the damage path area versus tornado intensity relationship. This larger database included all the tornadoes within the two-degree square between 1951 and 1996, plus all F-3, F-4, and F-5 tornadoes that occurred 
within Georgia and South Carolina, and all F-4 and F-5 tornadoes that occurred within Alabama between 1951 and 1996 (see Figure 1). Additional breakdowns of the tornado database can be found in Appendices II and III.

\section{Model}

The model used to determine the tornado risk probabilities was based on the Lu-McDonald modified IDTR model as described by $\mathrm{Lu}$ (1995). The features of this model include: (1) geometric point interpretation of the tornado hazard probability, (2) estimating the tornado occurrence using a Poisson process, (3) log-linear regression for estimating the average damage path per F-scale category tornado, (4) tornado F-scale misclassification errors based on a truncated normal distribution, and (5) intensity variations within the average damage path as a function of the tornado wind field model obtained from the Super Outbreak Tornadoes of April 3-4, 1974 (Mehta, et al., 1974).

Tornado hazard probability is expressed as the probability of tornado wind speeds exceeding some threshold value per year in a defined local region, $P\left(V \geq V_{s}\right)$. A number of assumptions are required for this model. These are:

- Tornado occurrences are independent; that is, the occurrence of one tornado occurs independently of any other tornado within a specific area and time frame.

- Tornado characteristics (damage path and intensity) are homogeneous in the geographical area and over the time period considered for the modeling process.

- Tornado F-scale misclassification errors are normally distributed based on a truncated normal distribution.

- The tornado intensity variation within the damage path is the same throughout the contiguous United States.

\section{Formulation of the Tornado Hazard Probability Model}

The probability of the tornado wind speed being equal to some value $V_{j}$ at least once in a time period $T$ in a given region $A$ is

$$
P_{T}\left(V=V_{j}\right)=\sum_{N=0}^{\infty} P\left(V_{j} \mid N\right) P_{T}(N)
$$

where $V_{j}$ is a range of wind speed associated with the F-scale category tornado $F_{j}$,

$T$ is the number of years considered in estimating the occurrence probability,

$\mathrm{N}$ is the number of tornadoes during the time pe$\operatorname{riod} \mathrm{T}$ in the region $\mathrm{A}$,
$\mathrm{P}_{\mathrm{T}}(\mathrm{N}) \quad$ is the probability of $\mathrm{N}$ tornado occurrences in the time period and region, and

$P\left(V_{T} \mid N\right)$ is the conditional probability of tornado wind speed in the range $V_{j}$ given $N$ tornadoes.

The tornado arrival process is assumed to be a Poisson process, where $u$ is the mean or expected value of the Poisson distribution. The mean or expected value is estimated as the number of tornadoes observed in the region divided by the number of years considered. The tornado probability in Eq. (2) is interpreted as the probability of a tornado of wind speed equal to a threshold value in any year touching down or lifting off anywhere within the specified area of concern. The $T$ index can be omitted or assumed to be for 1 year and Eq. (2) becomes

$P\left(V=V_{j}\right)=u P\left(V_{j}\right)$.

$\mathrm{P}\left(\mathrm{V}_{\mathrm{j}}\right)$ is based on the geometric point interpretation of probability where $a_{j}$ is the expected damage area associated with a tornado of wind speed $V_{j}$ and $A_{\text {eff }}$ is the total area for the region of concern (minus any areas for which tornadoes are unlikely to occur such as large bodies of water or very mountainous regions).

$P\left(V_{j}\right)=a_{j} / A_{\text {eff }}$

If the wind speed were constant over the entire damage path of a tornado of F-scale, $F_{j}$, then the expected damage area would be equal to the expected damage area for a tornado of intensity $F_{i}$. However, given a tornado of F-scale $F_{k}$, the true expected damage area associated with only those wind speeds in the range $V_{j}$ is given by

$a_{j}=\sum_{k \geq j}^{5} P\left(V_{j} \mid V_{k}\right) a_{k}^{\prime}$

where $a_{k}^{\prime}$ is the area represented by Eq. (6), below.

If $\mathrm{P}_{\mathrm{A}}\left(\mathrm{F}_{\mathrm{k}}\right)$ represents the percent of the tornado population that are true $F_{k}$ tornadoes, then the contribution to the damage path area from an $F_{k}$ tornado is the probability of seeing an $F_{k}$ tornado times its damage path area and is given by

$\mathrm{a}_{\mathrm{k}}^{\prime}=\mathrm{P}_{\mathrm{A}}\left(\mathrm{F}_{\mathrm{k}}\right) \mathrm{a}_{\mathrm{k}}$

where $a_{k}{ }^{\prime \prime}$ is the average or expected total damage path area associated with an $F_{k}$ tornado. $P_{A}\left(F_{k}\right)$ is the probability that an $F_{k}$ tornado has occurred and is correctly classified as an $F_{k}$ scale tornado. $P_{A}\left(F_{k}\right)$ is estimated by the proportion of observed tornadoes that are recorded as $F_{1}$ scale tornadoes modified by the chance that the F-scale classification was in error and the tornado should have been classified as an $F_{k}$ tornado summed over all recorded F-scales. 


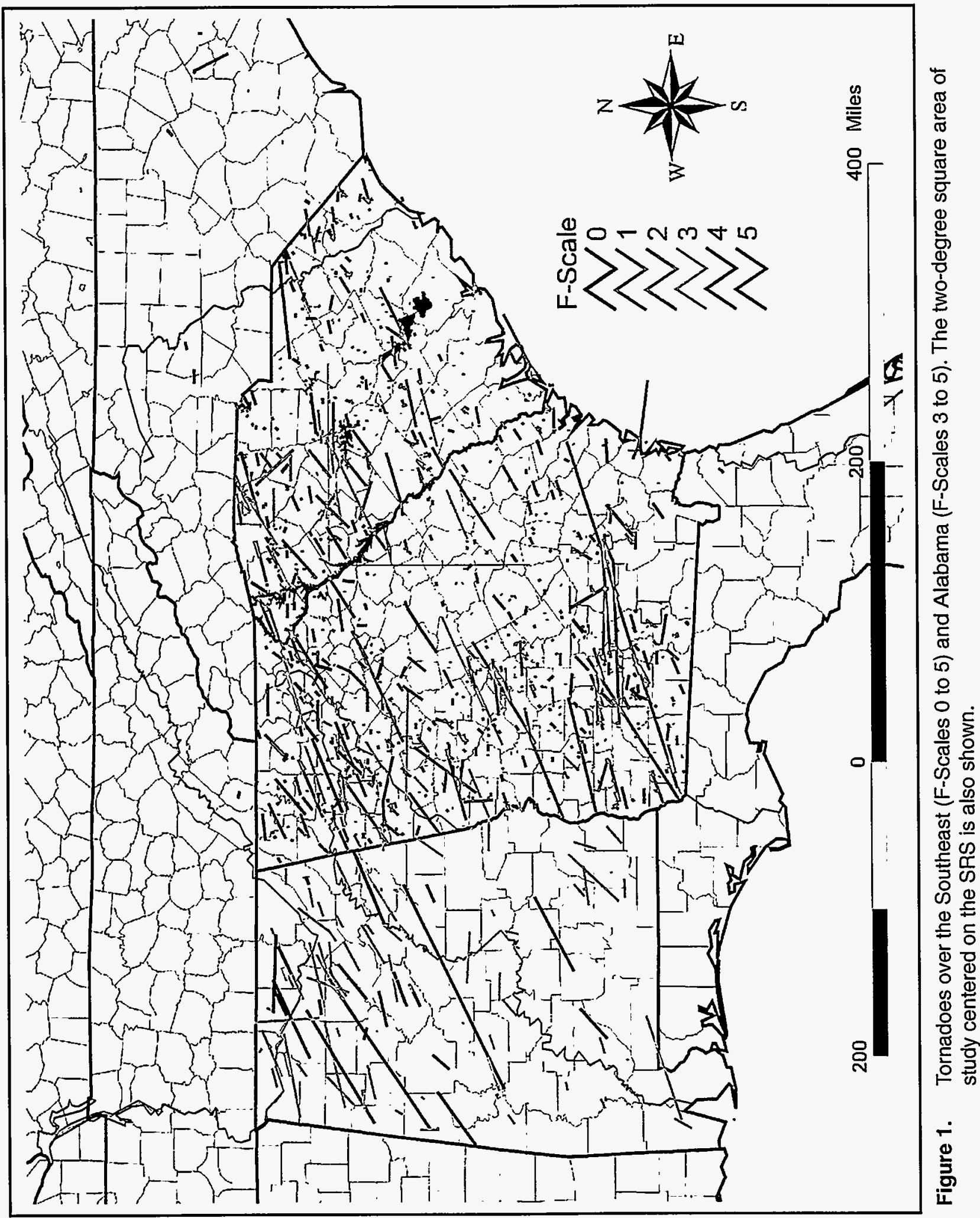


Let $\mathrm{P}_{\mathrm{A} \mid \mathrm{o}}\left(\mathrm{F}_{\mathrm{K}} \mid \mathrm{F}_{1}\right)$ be the conditional misclassification probability in which the tornado was recorded as an $F_{1}$ scale tornado but should have been recorded as an $F_{k}$ tornado, and $P_{0}\left(F_{1}\right)$ be the distribution of recorded $F_{1}$ scale tornadoes. Then the true proportion of $\mathrm{F}_{\mathrm{x}}$ scale tornadoes is given by

$$
\mathrm{P}_{\mathrm{A}}\left(\mathrm{F}_{\mathrm{k}}\right)=\sum_{1=0}^{5} \mathrm{P}_{\mathrm{A} \mid 0}\left(\mathrm{~F}_{\mathrm{k}} \mid \mathrm{F}_{1}\right) \mathrm{P}_{0}\left(\mathrm{~F}_{1}\right)
$$

Combining these equations gives the probability of experiencing a wind speed of $V_{j}$ in a year anywhere in the region defined by $A_{\text {err }}$

$$
\begin{gathered}
\mathrm{P}\left(\mathrm{V}=\mathrm{V}_{\mathrm{i}}\right)=\left(\mathrm{u} / \mathrm{A}_{\text {eff }}\right) \sum_{\mathrm{i} \leq \mathrm{k}}^{5} \mathrm{P}\left(\mathrm{V}_{\mathrm{i}} \mid \mathrm{V}_{\mathrm{k}}\right) \\
{\left[\sum_{1=0}^{5} \mathrm{P}_{\mathrm{A} \mid \mathrm{0}}\left(\mathrm{F}_{\mathrm{k}} \mid \mathrm{F}_{\mathrm{l}}\right) \mathrm{P}_{0}\left(\mathrm{~F}_{1}\right)\right] \mathrm{a}_{\mathrm{k}}^{\prime \prime \prime}}
\end{gathered}
$$

The terms in Eq. (8) are estimated by

a: $\quad$ number of tornadoes that occurred in the region $A$ divided by the number of years considered $(N / T)$,

$\hat{\mathrm{P}}_{0}\left(\mathrm{~F}_{1}\right): \quad$ proportion of $\mathrm{F}_{1}$ scale tornadoes observed in the region A over the time period,

$\hat{\mathrm{P}}_{\mathrm{AlO}}\left(\mathrm{F}_{\mathbf{k}} \mid \mathrm{F}_{\mathrm{f}}\right):$ misclassification conditional probability of reporting a tornado as $F_{1}$, given the tornado was an $F_{k}$ category,

$\hat{a}^{\prime \prime}{ }_{\aleph}: \quad$ expected average damage path area associated with an $F_{k}$ scale tornado for the given region, and

$\hat{\mathrm{P}}\left(\mathrm{V}_{\mathrm{i}} \mid \mathrm{V}_{\mathrm{k}}\right): \quad$ conditional probability of the wind speed being $V_{i}$ given a tornado is an $F_{x}$-scale tornado, $i \leq k$.

Since the probability of interest is for tornadic winds of equal to or greater than $V_{i}$, the total probability is summed for all wind speeds exceeding $V_{1}$ or

$$
\begin{gathered}
\hat{\mathrm{P}}\left(\mathrm{V} \geq \mathrm{V}_{\mathrm{i}}\right)=\sum_{\mathrm{i}=\mathrm{j}}^{5} \hat{\mathrm{u}}\left(\mathrm{V}_{\mathrm{j}}\right)=\left(\hat{\mathrm{u}} / \mathrm{A}_{\text {eff }}\right) \sum_{\mathrm{i}=\mathrm{j}}^{5} \sum_{k=0}^{5} \hat{\mathrm{P}}\left(\mathrm{V}_{\mathrm{i}} \mid \mathrm{V}_{k}\right) \\
{\left[\sum_{1=0}^{5} \hat{\mathrm{P}}_{\mathrm{A} \mid \mathrm{O}}\left(\mathrm{F}_{\mathrm{k}} \mid \mathrm{F}_{1}\right) \hat{\mathrm{P}}_{0}\left(\mathrm{~F}_{1}\right)\right] \hat{a}_{\mathrm{k}}}
\end{gathered}
$$

The wind speed ranges for three-second gusts for each Fclass were used in Eq. (9). In particular, the minimum wind speed for a three-second gust was used for $V_{i}$.

\section{Estimation of Average or Expected Damage Area}

Different methods can be used to estimate the mean damage area per F-scale category tornado. One method is to use the actual recorded damage area (recorded path length times recorded path width); another method is to use the Pearson path length and Pearson path width scales (PP Scales) (Fujita Pearson, 1973); and another is to use the observed lengths and predict the width to model the average damage area. This last method was employed by Lu (1995) to give a smoothed and more reliable estimate of the expected damage path area for each F-scale.

Based on a correlation analysis among path length, path width and intensity for tornadoes east of the Rocky Mountains, Lu (1995) showed these three parameters are not independent. An empirical relationship was derived from 19,831 tornado records on the database east of the Rocky Mountains. This relationship gives a predicted or modified path width based on the observed length, $L$ in miles, and $V_{j}$ in mph as the median of the range three-second gust wind speed for each $F_{j}$ tornado. The relationship is given in Eq. (10)

$$
\begin{array}{r}
\tilde{W}_{o}(j)=-0.05363+0.00138 \mathrm{~L}+ \\
0.0011 \mathrm{~V}_{j}+0.00001\left(\mathrm{~V}_{j}\right)(\mathrm{L}) .
\end{array}
$$

For each observed tornado, a predicted width is obtained using Eq. (10). The damage area for each tornado is computed by multiplying the predicted width (miles) from Eq. (10) times the observed length (miles). Using the predicted damage path width instead of the reported damage path width is based on expert opinion (McDonald) and reflects the belief that the reported width is in error and the predicted width is a better estimator.

\section{Log-Linear Regression to Predict the Average Damage Area per F-Scale Tornado}

There is considerable variation in the damage areas within F-scales. Damage area can vary by geographical region and depends on the local topography and meteorological conditions. The set of tornadoes used to derive an expected damage path area for a given F-scale intensity tornado should reflect the expected damage path by intensity distribution . expected for the region of concern.

Lu (1995) recommended using a log-linear regression to estimate the expected damage path area for each F-scale class tornado. The method recommended is to first trans- 
form the damage path area by taking the logarithm to the base 10 as the dependent variable. Next the logarithm to the base 10 is taken of the median of the range of wind speeds for the three-second gusts for each F-scale class as the independent variable. A linear regression is fit to the log-tranforned variables. The relationship is given in Eq. (11).

$\log ($ Area $)=C_{0}+C_{1} \log \left(\right.$ median Wind speed $V_{j}$ )

Eq. (11) can be fit using two methods that (under some conditions) will give essentially the same results. All methods use the log of the median wind speed as the independent variable in the regression. One method is to calculate the average of the log-transformed areas for each F-scale category for the dependent variable. The regression is done using the average of the log-transformed areas. If this method is used, it is important that each mean be estimated with approximately the same reliability (same number of tornadoes per F-class). This method will have only 4 degrees of freedom for the mean square error in the regression. The other method is to use a weighted estimate based on all the data. Both methods are acceptable, but if there are not approximately equal numbers of tornadoes per F-scale or there are missing F-scale tornadoes, the two methods will give different regressions. In using either method, it is important to compare the variability within each F-scale since the regression assumes a pooled estimate of error. Using all the data permits a test of (1) whether the pooled error is appropriate and the variances are the same for all $F$-classes and (2) whether the lack of fit of the model is significant compared with the pooled error variance. There are also more degrees of freedom for the mean square error. (If the regression is done using only the means of the transformed variables, then the mean square error is the lack of fit of the model confounded with the variability in estimating the means, and cannot be separated.)

\section{Non-Rated and Unreported Tornadoes}

If there are a large number of non-rated tornadoes, then several methods can be used to assign an F-scale to these tornadoes. If there are few non-rated tornadoes compared with the total number of rated tornadoes, then one can omit the non-rated tornadoes when determining the tornado intensity and area-intensity occurrence, but include them when counting the total tornado frequency. Most methods assume the distribution for the non-rated tornadoes is the same as for the rated tornadoes. There was only one non-rated tornado within the two-degree square used for the tornado analysis. Non-rated tornadoes in Georgia and South Carolina were randomly assigned an F-scale based on the distribution of the rated tornadoes.
More troublesome are unreported tornadoes. The LuMcDonald model does not include a mechanism for including unreported tornadoes. Unreported tornadoes generally occur in the lower F-scale categories. Using more recent time periods lowers the chance for unreported tornadoes since the reporting and identification process has improved considerably since 1950 .

There is no consensus on how to handle unreported tornadoes. Consequently, it is important to ensure that the database is up-to-date, as complete as possible, and compared with all available sources of tornado data so as to minimize the possibility of unreported tornadoes.

\section{Misclassification Errors}

A truncated normal probability distribution function is used by Lu-McDonald to model the probabilities of misclassification error. Let $\mathrm{P}_{\mathrm{AlO}}\left(\mathrm{F}_{\mathrm{i}} \mid \mathrm{F}_{\mathrm{j}}\right)$ represent the conditional probability of reporting a true $F_{j}$ tornado as an $F_{i}$ tornado. For each tornado classified as $F_{i}$, the mean value is estimated as the $F_{i}$ scale (i) and the standard deviation is estimated assuming the misclassification is plus or minus one F-scale category (at the $95 \%$ confidence level). The standard deviation is determined by solving

$$
1=Z_{(1-\alpha 2)} \sigma \text {, }
$$

where $Z_{(1-\alpha 2)} \sigma$, is the $100(1-\alpha / 2)$ percentile of the normal distribution. For the $95 \%$ confidence level, $\alpha=0.05$ and $\mathrm{Z}_{(0.975)} \approx 2$ so that

$$
\sigma=1 / 2=0.5 \text {. }
$$

The conditional probabilities $\mathrm{P}_{\mathrm{AlO}}\left(\mathrm{F}_{\mathrm{i}} \mid \mathrm{F}_{\mathrm{j}}\right)$ can be found as

$$
\begin{gathered}
\mathrm{P}_{\mathrm{Al} 0}\left(\mathrm{~F}_{0} \mid \mathrm{F}_{0}\right)=\Phi((0.5-0) / 0.5)=\Phi(1.0)=0.8413 \\
\mathrm{P}_{\mathrm{AO}}\left(\mathrm{F}_{1} \mid \mathrm{F}_{0}\right)=\Phi((1.5-0) / 0.5)- \\
\Phi((0.5-0) / 0.5)=\Phi(3)-\Phi(1)=0.1574 \\
\mathrm{P}_{\mathrm{AlO}}\left(\mathrm{F}_{2} \mid \mathrm{F}_{0}\right)=\Phi((2.5-0) / 0.5)- \\
\Phi((1.5-0) / 0.5)=\Phi(5)-\Phi(3)=0.0013 .
\end{gathered}
$$

A matrix of conditional probabilities are constructed similar to those given for the $\mathrm{F}_{\mathrm{o}}$ scale tornado.

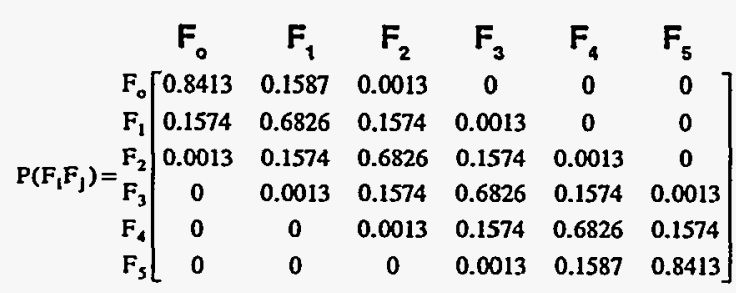


The matrix in Eq. (12) is then multiplied in matrix fashion by the probability of reporting an $F_{i}$ tornado estimated from the observed region.

\section{Intensity Variations within the Damage Path}

The tornado intensity can be represented by the variation of tornado intensity along the path length and path width. The variation of intensity along the length of a tornado path in the Lu-McDonald model was obtained from the Super Outbreak Tornadoes of April 3-4, 1974 (Mehta, et al., 1975). McDonald proposed a combined Rankine vortex model to emulate tornado intensity variation across the path width. The combinations of these two variations are the conditional matrix given in (13).

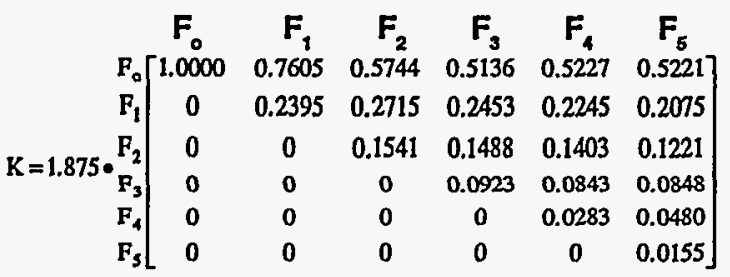

The elements of this matrix can be interpreted as conditional probabilities, which adjust for variation of wind speed along the damage area. If the maximum wind speed associated with tornado scale $F_{j}$ is $V_{j}$ then the area associated with a maximum wind speed for tornado scale $F_{i}, i \leq j$, is $\hat{P}\left(V_{i} \mid V_{j}\right)$. The coefficient 1.875, which multiplies all the elements in the matrix, is the ratio of the actual damage path area bounded by $40 \mathrm{mph}$ wind speed to visible damage path area which is bounded by $75 \mathrm{mph}$ wind speed (McDonald, 1981).

\section{Results for Tornadoes}

As stated earlier, the region used for estimating the tornado occurrence and the occurrence-intensity distribution was a two-degree square centered at $33.25 \mathrm{~N} 81.63 \mathrm{~W}$. There were 165 tornadoes used for the occurrence-intensity distribution for an average frequency in those 30 years (between 1967-1996) of 5.5 tornadoes per year. The area of the twodegree region excluding the area in the Atlantic Ocean and covering large bodies of water or steep mountainous regions is $15,588.85 \mathrm{sq} \mathrm{mi}$. Thus for the SRS

$\hat{\mathrm{u}} / \mathrm{A}_{\mathrm{eff}}=5.5 / 15,588.85=0.000352816$.

The occurrence-intensity distribution is given in Table V.

After adjusting for misclassification (multiplying by the conditional probabilities given in [(12)]), the intensity/occurrence relationship is given in Table VI.

There are no F-5 tornadoes and only two F-4 and eight F-3 tornadoes within the two-degree square. In order to estimate the average path area per tornado, additional F-3, F-4, and F-5 tornadoes are needed. All F-3 and F-4 tornadoes that occurred in Georgia and South Carolina and all F-4 and F-5 tornadoes that occurred in Alabama were included as well as all the F-0, F-1, and F-2 tornadoes within the twodegree square between 1951 through 1966 . This yielded 206 tornadoes between $\mathrm{F}-0$ and $\mathrm{F}-4$ from within the two-degree square, an additional 51 F-3 and $15 \mathrm{~F}-4$ tornadoes from South Carolina and Georgia, and 17 F-4 and 6 F-5 tornadoes from the state of Alabama for a total of 295 tornadoes to determine the area-intensity relationship.

Table V. Occurrence-Intensity Distribution for the Two-Degree Square Centered at 33.25 N 81.63 W from 1967 through 1996

\begin{tabular}{|lccccccc|}
\hline F-Scale & F-0 & F-1 & F-2 & F-3 & F-4 & F-5 \\
\hline No. Tomadoes & 35 & 83 & 37 & 8 & 2 & 0 \\
\hline \multirow{2}{*}{ Proportion } & 0.21212 & 0.50303 & 0.22424 & 0.04848 & 0.01212 & 0.0 \\
\hline
\end{tabular}

Table VI. Intensity-Occurrence Distribution Adjusted for Misclassification

\begin{tabular}{|lccccccc|}
\hline F-Scale & F-0 & F-1 & & F-2 & F-3 & F-4 & F-5 \\
\hline No. Tornadoes & 35 & 83 & & 37 & 8 & 2 & 0 \\
\hline Adjusted Proportion & 0.25858 & 0.41212 & 0.24017 & 0.07095 & 0.01620 & 0.00199 \\
\hline
\end{tabular}


Before computing the average area for each F-class, the path width for each of the 295 tornadoes was predicted using Eq. (10). The damage path area for individual tornadoes was computed by

Area-j $=$ predicted width- $\mathrm{j}$ times observed length- $\mathrm{j}$.

Then a log-linear regression model was fit to the logarithm (base 10) of the area as the dependent variable and the logarithm (base 10) of the median three-second gust wind speed for the observed F-scale category as the independent variable. The regression was done for three models: (1) the observed areas (prior to replacing the observed width by the predicted width), (2) the observed areas after replacing the observed width by the predicted width), and (3) computing the average log-transformed area (with predicted width) and fitting the regression using only the six F-class mean transformed areas.

Methods (2) and (3) compare the results due to unequal numbers of tornadoes by F-class. Comparing results from methods (2) and (1) define the effect of replacing the observed damage path width by the predicted damage path width. Replacing the observed width by the predicted width decreased the variability within F-class. The F-class logtransformed area variability was essentially the same across all classes for Method (2). Thus Method (2) is preferred over Method (1). Method (2) is also preferred over Method (3) since Method (3) assumes equal numbers of tornadoes per F-class. The results of the regression for each of the three methods are:
(1) Using observed widths, all tornadoes: Area = $\left.10^{(4.645358} \log (\gamma)-10.606158\right)$.

(2) Using predicted widths, all tornadoes: Area = $10^{\left(4.917048^{*} \log (\mathrm{V})-11.000696\right)}$

(3) Using predicted widths, average per class: Area = $10^{(4.892737 * \log (V)-10992590)}$.

The regressions using all three methods will result in similar but not identical expected areas for each F-class tornado. Table VII gives the observed average area, the average area using the predicted widths, and the smoothed and predicted average area per F-class tornado based on Method (2).

The predicted areas were multiplied by the intensity-occurrence conditional probabilities (adjusted for misclassification) to get the occurrence-intensity areas, and then multiplied by the conditional wind speed proportions (matrix from (13)). The area due to each F-class tornado is then given in Table VIII.

These areas were multiplied by $\hat{u} / A_{\text {eff }}$ or 0.000352816 and summed to get the probabilities given in Table IX for threesecond wind speeds (minimum value for the wind speed range in each F-class).

To get probabilities for other wind speeds, interpolation is required. The wind speed is considered to be linear within each F-class if the base 10 logarithm of the corresponding probability is used. Inversely, the wind speed correspond-

\section{Table VII. Predicted and Observed Average Areas per F-Class Tornado}

\begin{tabular}{|c|c|c|c|}
\hline Fiscale & $=6$ & F-1 : : & F-2. \\
\hline Womadoes & $4 x^{3}+42$ & 108 & 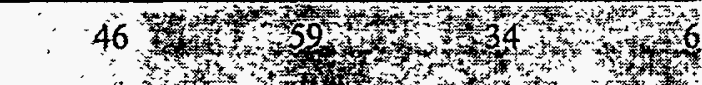 \\
\hline Average Observed Area & 0.02888 & $0: 19046$ & $1.25662,55,67431] \quad 9,83199 \quad 863068$ \\
\hline Width Predicted Average Area & 0.0179 & 0.2749 & $42061 \quad 108504 \quad 172693$ \\
\hline Predicted Area using Method (2) & 0.0062 & 0.0617 & $14220,4.5973 \quad 127938$ \\
\hline
\end{tabular}

Table VIIl. Area by F-Scale Tornado after Adjusting for Misclassification and Path Area Variation

\begin{tabular}{|c|c|c|c|c|c|}
\hline Fiscale & F-0 & F-1 & F-2 & $\therefore \quad F=4$ & $\mathrm{~F}_{-5}$ \\
\hline Avetge Area (sq mi) & 0.32411 & 0.14154 & 0,07765 & $0.03315 \quad 0.00620$ & 000074 \\
\hline
\end{tabular}


ing to a given probability can be obtained by log-linear interpolation from Table IX. Two wind speeds of interest in the risk analyses are the wind speeds corresponding to a probability of $2 \times 10^{-5}$ and $2 \times 10^{-6}$. These can be obtained following the example for $2 \times 10^{-5}$ or

$$
\begin{gathered}
V\left(2 \times 10^{-5}\right)=118+(162-118)\left[\left(\log _{10}\left(2 \times 10^{-5}\right)-\log _{10}\right.\right. \\
\left.\left(4.15 \times 10^{-5}\right)\right] /\left[\left(\log _{10}\left(1.41 \times 10^{-5}\right)-\log _{10}\right.\right. \\
\left.\left(4.15 \times 10^{-5}\right)\right]=147.8 .
\end{gathered}
$$

The wind speed, $V_{0}$, such that $P\left(V \geq V_{0}\right)=$ $2 \times 10^{-5}$ is $148 \mathrm{mph}$.

The wind speed, $V_{0}$, such that $P\left(V \geq V_{0}\right)=$ $2 \times 10^{-6}$ is $215 \mathrm{mph}$.

The set of tornadoes used in the analysis is given in Appen$\operatorname{dix}$ I. SAS ${ }^{\oplus}$ was used to do the analyses and the regression.

To ensure that the Lu-McDonald model was correctly implemented, the Kansas City example given in $\mathrm{Lu}$ (1995) was verified using the same computer code. Individual tornado data was not provided for the Kansas City data, but by using the intensity-occurrence distribution and the average damage path area for each F-class, a set of tornadoes was formulated. The average damage path area was computed by replacing the observed width by the predicted width in Eq. (10). The Kansas City example ensures that the misclassification and wind speed variation conditional probabilities were correctly implemented and the regression was correctly done. For the Kansas City data, the regression had to be done using the log-transformation of each F-class average since individual damage path information was not available. The Kansas City example was also based on the F-class wind speeds for the fastest quarter mile rather than the three-second gust wind speeds.

\section{Wind Gusts}

\section{Wind Gust Data}

Wind gust data were obtained from a 1990-1996 SRS meteorological database and regional National Weather Service (NWS) observation stations. Data from the NWS stations was obtained from the National Climatic Data Center in Asheville, NC. Stations included were Columbia, SC; Augusta (Bush Field), Athens, and Macon, GA. Table X shows the available period of record for each NWS station. The wind gusts contained in these data most closely

Table IX. Probabilities for Three-Second Tornadic Wind Speeds (Minimum Value F-Class Wind Speed)

\begin{tabular}{|lccccccc|}
\hline $\begin{array}{l}\text { Minimum Wind } \\
\text { speed (mph) }\end{array}$ & 45 & & 79 & 118 & 162 & 210 & 262 \\
\hline $\begin{array}{l}\text { Probability of equal } \\
\text { or greafer wind speed }\end{array}$ & 0.000206 & 0.0000925 & 0.0000415 & 0.0000141 & 0.00000245 & 0.000000261 \\
\hline
\end{tabular}

Table X. Wind Gust Data Sources

\begin{tabular}{|llll|}
\hline Daily/Regional & & & \\
\hline Augusta, (Bush Field), GA & September 1972 & to & April 1994 \\
Columbia, SC & September 1971 & to & November 1995 \\
Athens, GA & July 1980 & to & January 1996 \\
Macon, GA & July 1972 & to & April 1994 \\
SRS & January 1,1990 & to & December 31, 1996 \\
Annual Maximum & & & \\
\hline Augusta (Bush Field) & 1950 & to & 1971 \\
\hline
\end{tabular}


resemble the 'three-second wind gust' for the purpose of hazard analyses. A daily highest three-second gust (in knots) was given for each day of the month in the period of record.

In each case, the end of the period of record fell within the period of record used for the SRS gust data. Therefore, no gaps existed in the wind gust data set after each period of record ended for the regional locations. Additionally, annual maximum wind gust data from Augusta dating back to 1950 were taken from Hunter (1989) to complete the data record through 1971 . The combination of the above data bases provides wind gust data for the 1950 through 1996 period.

\section{Model}

An extreme-value distribution was assumed for the yearly maximum wind gusts per 24-hour period. The maximum wind gust for each month was obtained for each station of interest, then the maximum wind gust by year for each station was determined. The average and standard deviation of the maximum yearly 24-hour wind gusts was computed using Eqs. 13 and 14. The individual yearly maximum wind gusts for each station were standardized (Eq. 15) and fit to the extreme-value distribution.

Let $\mathrm{X}_{\mathrm{ij}}$ be the ith yearly maximum 24 hour wind for station-j; then the mean, standard deviation, coefficient of variation (divided by $100 \%$ ), and standardized ijth value are given by

$$
\bar{x}_{j}=\sum_{i=1}^{n_{j}} x_{i j} / n_{j}
$$

$s_{j}=\sqrt{\sum_{i=1}^{n_{j}}\left(x_{i j}-\bar{x}_{j}\right)^{2} /\left(n_{j}-1\right)}$

$\tau_{i j}=\frac{X_{i j}-\bar{X}_{j}}{S_{j}}$

$C V_{j}=S_{j} / \bar{X}_{j}$

Table XI gives the means, standard deviations, and coefficient of variation for each station.

The standardized variables, were used to fit a generalized extreme-value distribution and to determine which of the three extreme type distributions were appropriate.

A single form of the three possible types of limiting distributions for extreme values has been derived by Fisher and Tippett (1928) and can be modeled by

$F(\tau)=\exp \left[-\{1-k(\tau-\xi) / \alpha\}^{1 / k}\right], k \neq 0$,

$\mathrm{F}(\tau)=\exp [-\exp \{-(\tau-\xi) / \alpha\}], \mathrm{k}=0$.

$\tau$ is bounded by $\xi+\alpha / \mathrm{k}$ from above if $\mathrm{k}>0$ and from below if $k<0$. Here $\xi$ and $\alpha$ are location and scale parameters, respectively. The shape parameter, $k$, determines which extreme-value distribution is best represented by the data. Fisher-Tippett Types I, II, and III correspond to $k=0, k<0$, and $\mathrm{k} 0$, respectively. In practice the shape parameter usually lies in the range $-(1 / 2)<k<(1 / 2)$. When this is the case, the following can be used to estimate the parameters, $\xi, \alpha$, and k (Hosking, et al., 1985).

Table XI. Means, Standard Deviations, and Coefficient of Variation by Station

\begin{tabular}{|lllll|}
\hline Station & $\begin{array}{l}\text { No, of } \\
\text { Years }\end{array}$ & Mean & $\begin{array}{l}\text { Standard } \\
\text { Deviation }\end{array}$ & $\begin{array}{l}\text { Coefficient of } \\
\text { Variation }(\div 100 \%) \\
\text { (CV) }\end{array}$ \\
\hline Augusta & 44 & 49.9910 & 11.0853 & 0.221747 \\
Athens & 18 & 54.9187 & 12.6914 & 0.231094 \\
Columbia & 25 & 53.8574 & 8.8395 & 0.164127 \\
Macon & 23 & 57.7401 & 11.4432 & 0.198185 \\
SRS & 9 & 62.3139 & 0.7352 & 0.011798 \\
\hline
\end{tabular}


$\hat{\mathrm{k}}=7.8590 \mathrm{c}+2.9554 \mathrm{c}^{2}$, where

$c=\frac{2 b_{1}-b_{0}}{3 b_{2}-b_{0}}-\frac{\log 2}{\log 3}$

The error in estimating $k$ using Eq. (19) is less than 0.0009 through the range $-(1 / 2)<k<(1 / 2)$.

Given $\hat{k}$, the scale and location parameters can be estimated successively by

$$
\begin{aligned}
& \hat{\alpha}=\frac{\left(2 b_{1}-b_{0}\right) \hat{k}}{\Gamma(1+\hat{k})\left(1-2^{-k}\right)} \\
& \hat{\xi}=b_{o}+\hat{\alpha}\{\Gamma(1+\hat{k})-1\} \hat{k}
\end{aligned}
$$

The Type I extreme-value distribution, or Gumbel distribution, is a particularly simple, special case of the generalized extreme-value (GEV) distribution, and it is often useful to test whether a given set of data is generated by a Gumbel rather than a GEV distribution. This is equivalent to testing whether the shape parameter, $k$, is zero in the GEV distribution. Assuming the null hypothesis $\mathrm{H}_{\mathrm{o}}: \mathrm{k}=0$, the estimator $\hat{\mathrm{k}}$ is asymptotically distributed as $\mathrm{N}(0,0.5633 / \mathrm{n})$. The test may be performed by comparing the statistic $Z=\hat{k}(n / 0.5633)^{1 / 2}$ with the critical values of a standard normal distribution. Significant positive values of $\mathrm{Z}$ imply rejection of $\mathrm{H}_{\mathrm{o}}$ in favor of the alternative $k>0$, and significant negative values of $\mathrm{Z}$ imply rejection in favor of $\mathrm{k}<0$.

For the wind gusts, the estimate of $\hat{\mathrm{k}}$ was 0.10957 , the $\mathrm{Z}$ ratio was 1.59261 , and the probability Z-ratio less than or equal to the value observed is 0.94438 . The probability of getting a larger Z-ratio is $1-0.944$ or 0.056 . Since the test is whether the true $\mathrm{k}$ is zero, a two-tailed test is desired (to detect a positive or negative $k$ ). Values of $Z$ (k-ratio) between -1.96 and +1.96 indicate that $k$ is not significantly different from zero with $95 \%$ confidence. For the wind gust, we can conclude the true $k$ is zero and an extreme value of type I can be úsed to determine the probability of getting a given maximum wind speed.

The values, $b_{0}, b_{1}$, and $b_{2}$ are estimated from the data using Eqs. (22) through (24) where the standardized variables $\tau_{i j}$ are ordered by size and $\mathrm{ij}$ is the rank.

$$
b_{0}=\sum_{i j=1}^{N} \tau_{i j}+N .
$$

$$
\begin{aligned}
& b_{1}=\frac{1}{N(N-1)} \sum_{i j=1}^{N}(i j-1) \tau_{i j} \\
& b_{2}=\frac{1}{N(N-1)(N-2)} \sum_{i j=1}^{N}(i j-1)(i j-2) \tau_{i j} .
\end{aligned}
$$

Since the wind gusts fit a Gumbel (type I) distribution, the parameters are re-estimated assuming $\mathrm{k}=0$ using the method of moments (Eliasson, 1997). For a Type I distribution,

$\hat{\alpha}=1 / 1.28255$

$\hat{\xi} / \hat{\alpha}=\hat{\beta}=0.57722$.

In order to determine the wind speed for return periods of concern $\tau$, Eq. (18) must be solved for each return period. $\tau$ is the standardized variable so that either the individual station's mean and standard deviation or the average CV over all stations and the individual station's 5-year wind speed is used (Eliasson, 1997).

Let $P$ be the return period of interest. Then $(1-1 / P)$ is the probability corresponding to a wind speed $\geq V_{p}$ or

$\operatorname{Prob}\left(V \geq V_{p}\right)=(1-1 / P)=\exp$

$$
\left[-\left\{\exp \left[-\left(1.28255\left(\tau_{p}\right)+0.5772\right)\right]\right\}\right] \text {, }
$$

where

$\tau_{\mathrm{ij}}=\left(\mathrm{X}_{\mathrm{p}}-\mathrm{X}_{\mathrm{j}}\right) / \mathrm{S}_{\mathrm{j}}$

and $\bar{X}_{j}$ is the $\mathrm{j}$-th station mean and $S_{j}$ is the station standard deviation.

$\mathrm{X}_{\mathrm{p}}=\mathrm{S}_{\mathrm{j}}(\log [-\log [-(1-1 / \mathrm{P})\}]-0.57722)$

$$
(1 / 1.28255)+\bar{X}_{j}
$$

Eliasson (1997) indicates that oftentimes a smoother fit can be obtained by using the coefficient of variation averaged over all stations. Eliasson also gives an alternate method to Eq. (28) using the 5-year return wind speed, which should always be within the observations. Both Eq. (28) and Eq. (29) in which the individual station's $\mathrm{CV}_{\mathrm{j}}$ and the 5-year return wind speed, denoted by $\mathrm{MS}_{\mathrm{j}}$ are used to obtain the wind speed for station $\mathrm{j}$ and return period $\mathrm{P}$.

$\mathrm{X}_{\mathrm{p}}=\mathrm{M} 5_{\mathrm{j}}\left[1+\mathrm{C}_{\mathrm{i}}(\mathrm{y}-1.5)\right]$.

where $y=\log (-\log (1(1-1 / P)))$,

$M 5_{j}=S_{j}\{(0.8-0.57722) / 1.28255\}+X_{j}$, 
$C_{i}=0.78 /\left\{\left(1 / C V_{j}\right)+0.72\right\}$

If the coefficient of variation, $\mathrm{CV}$, is averaged over all stations, $\mathrm{CV}_{\mathrm{a}}$, then replace the $\mathrm{C}_{\mathrm{i}}$ in Eqs. (31) and (29) by $\mathrm{C}_{\mathrm{a}}$ where

$\mathrm{C}_{\mathrm{z}}=0.78 /\left\{\left(1 / \mathrm{CV}_{\mathrm{a}}\right)+0.72\right\}$

For all but the SRS station, the individual station's coefficient of variation and the average coefficient of variation are approximately the same, so either could be used. However for the SRS station, the station mean is approximately the same as the other stations, but the variability is very small. This may be due to the fewer number of years for which data has been collected or the method of measuring the wind gust. For this station, the average coefficient of variation was used to compute the wind speed using Eq. (29) instead of Eq. (28). This gave more realistic values that were comparable to other stations within the same area.

The average coefficient of variation was 0.1917 compared with the individual station values of 0.2217 for Augusta, 0.2311 for Athens, 0.1641 for Columbia, 0.1982 for Macon and 0.0118 for SRS. There is not much difference between the station CV and the average CV except for SRS.

\section{Summary of Tornadic Wind and Wind Gusts}

Figure 2 shows the return frequencies for maximum wind speeds associated with tornadoes and wind gusts for the SRS. Key points on the curve for the tornadic winds include $148 \mathrm{mph}$ every 50,000 years $\left(2 \times 10^{-5}\right)$ and $215 \mathrm{mph}$

Table XII. Tornadic Wind Speeds (Three-Second Gusts) with Return Period and Probability

\begin{tabular}{|ccc|}
\hline $\begin{array}{c}\text { Tornadic Winds } \\
\text { (Three-Sec. Gusts) } \\
(\mathrm{mph})\end{array}$ & ReturnPeriod & Probability \\
\hline 45 & $(\mathrm{yrs})$ & \\
79 & 4858.4 & 0.00020583 \\
118 & 10931.4 & 0.00009148 \\
162 & 24073.2 & 0.00004154 \\
210 & 70721.4 & 0.00001414 \\
262 & 408163.3 & 0.000000245 \\
\hline
\end{tabular}

for every 500,000 years $\left(2 \times 10^{-6}\right)$. For wind gusts, a speed of $83 \mathrm{mph}$ can be expected in a 50 year period $\left(2 \times 10^{-2}\right)$, $107 \mathrm{mph}$ in a 1,000 year period $\left(1 \times 10^{-3}\right)$, and $126 \mathrm{mph}$ in a 10,000 year period $\left(1 \times 10^{-4}\right)$. Tables XII-XIII show the data in a tabular format.

\section{Extreme Rainfall}

\section{Databases}

Calculations of extreme precipitation frequencies were based on 15-minute rainfall data from three National Climatic Data Center (NCDC) cooperative stations near SRS, hourly rainfall from eight nearby National Weather Service (NWS), and four cooperative stations, and daily rainfall from four rain gauge stations located on the SRS. Data sources are summarized in Tables XIV and XV.

The eight cooperative and NWS stations were selected based on: (1) proximity to the SRS (within about $100 \mathrm{~km}$ ) and (2) geographic similarity, i.e., located either in the upper coastal plain or lower piedmont regions of South Carolina and Georgia. The fifteen-minute and hourly data for

Table XIII. Wind Gusts (Three-Second Gusts) with Return Period and Probability

\begin{tabular}{|ccc|}
\hline $\begin{array}{c}\text { Wind Gusts } \\
\text { (Three-Sec. Gusts) } \\
\text { (mph) }\end{array}$ & Return Period & Probability \\
\hline & (yrs) & \\
62.8424 & 5 & 0.2 \\
69.0377 & 10 & 0.1 \\
76.8654 & 25 & 0.04 \\
82.6725 & 50 & 0.02 \\
88.4367 & 100 & 0.01 \\
91.798 & 150 & 0.0067 \\
94.1799 & 200 & 0.005 \\
96.0262 & 250 & 0.004 \\
101.7569 & 500 & 0.002 \\
107.4835 & 1000 & 0.001 \\
110.8322 & 1500 & 0.00067 \\
113.2079 & 2000 & 0.0005 \\
120.7738 & 5000 & 0.0002 \\
126.4966 & 10000 & 0.0001 \\
139.7839 & 50000 & 0.00002 \\
145.5064 & 100000 & 0.00001 \\
\hline
\end{tabular}




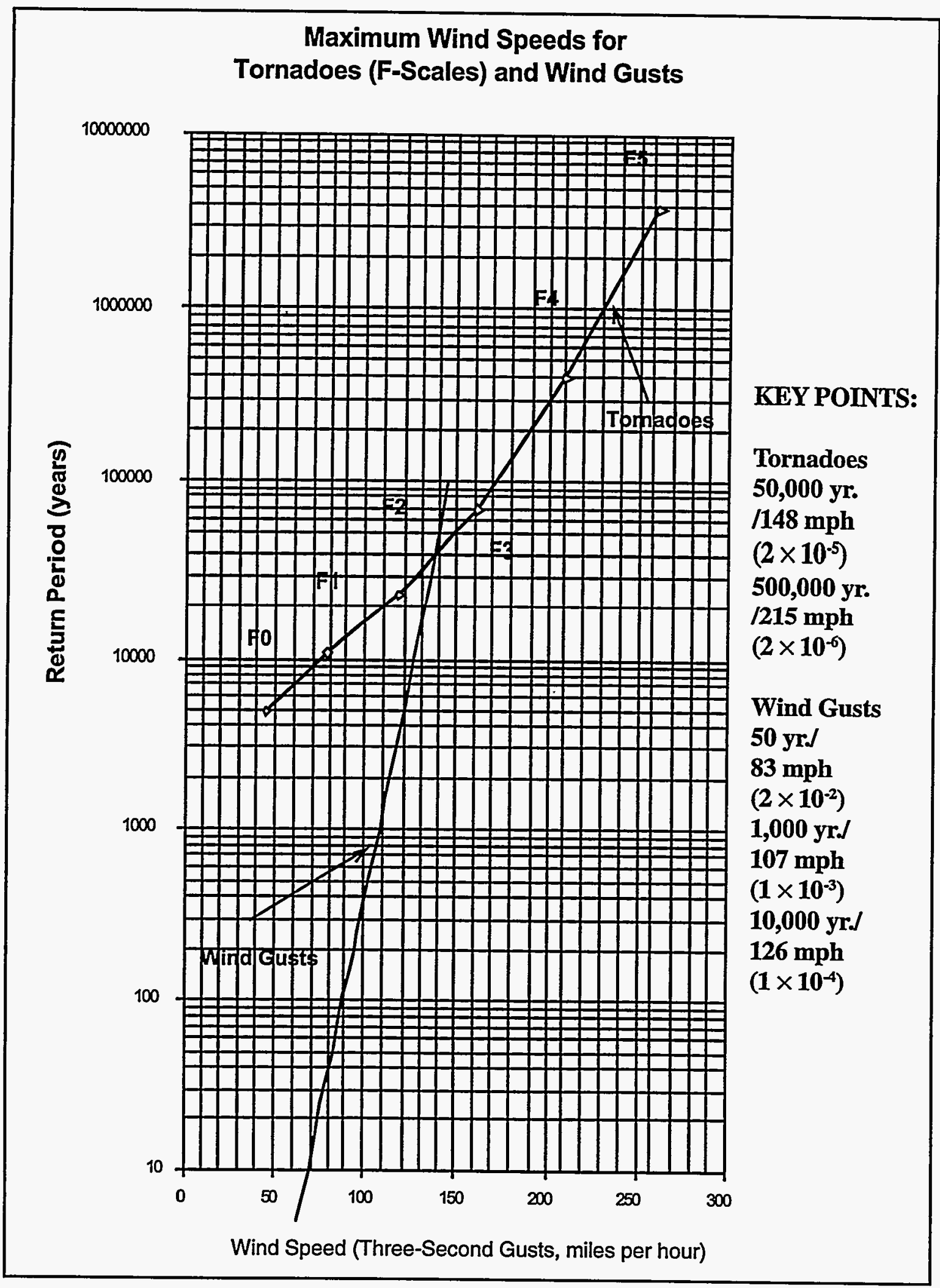

Figure 2. Maximum Wind Speeds (Three-Second Gusts) for Tornadoes (F-Scales) and Wind Gusts 
Table XIV. Stations with Daily Precipitation Data

\begin{tabular}{|c|c|c|c|c|}
\hline Station & $\begin{array}{c}\text { Location } \\
\text { (Latitude, Longitude) }\end{array}$ & $\begin{array}{l}\text { Elevation } \\
\text { (m) }\end{array}$ & $\begin{array}{l}\text { Period of Record } \\
\text { (mo/yr) }\end{array}$ & Years \\
\hline Augusta, GA NWS & $33: 22: 00 \mathrm{~N}, 81: 58: 00 \mathrm{~W}$ & 45 & $1 / 49$ thru $12 / 95$ & 47 \\
\hline Macon, GANWS & $32: 42: 00 \mathrm{~N}, 83: 39: 00 \mathrm{~W}$ & 108 & $1 / 49$ thru $12 / 95$ & 47 \\
\hline Athens, GA NWS & $33: 57: 00 \mathrm{~N}, 83: 19: 00 \mathrm{~W}$ & 244 & $1 / 58$ thru $12 / 95$ & 38 \\
\hline \multirow[t]{2}{*}{ Sylvania, GA.2SSE * } & $32: 44: 00 \mathrm{~N}, 81: 37: 00 \mathrm{~W}$ & 76 & $1 / 49$ thru $12 / 95$ & 47 \\
\hline & & & 1/71 thru 12195. & 25 \\
\hline Louisville, GA IE* & $33: 01: 00 \mathrm{~N}, 82: 24: 00 \mathrm{~W}$ & 98 & $\begin{array}{l}1 / 49 \text { thru } 12 / 95 \\
1 / 71 \text { thru } 12 / 95\end{array}$ & $\begin{array}{l}47 \\
25\end{array}$ \\
\hline
\end{tabular}

* Co-operative stations providing 15-minute rainfall. Period of record for the 15-minute data are italicized.

Table XV. Stations with Hourly Precipitation Data

\begin{tabular}{|llccc|}
\hline Station & $\begin{array}{c}\text { Location } \\
\text { (Latitude, Longitude) }\end{array}$ & $\begin{array}{c}\text { Elevation } \\
\text { (m) }\end{array}$ & $\begin{array}{c}\text { Period of Record } \\
\text { (mo/yr) }\end{array}$ & Years \\
\hline SRTC & $33: 21: 00 \mathrm{~N}, 81: 44: 00 \mathrm{~W}$ & 107 & $1 / 68$ thru 12/97 & 30 \\
Barricade 3 & $33: 21: 00 \mathrm{~N}, 81: 30: 00 \mathrm{~W}$ & 91 & $1 / 64$ thru 12/97 & 34 \\
Barricade 5 & $33: 07: 00 \mathrm{~N}, 81: 36: 00 \mathrm{~W}$ & 50 & $1 / 70$ thru 12/97 & 28 \\
200-F & $33: 17: 00 \mathrm{~N}, 81: 40: 00 \mathrm{~W}$ & 90 & $1 / 61$ thru 12/97 & 37 \\
\hline
\end{tabular}


these stations were extracted from compact disks containing NCDC TD-3260 and TD-3240 data sets, respectively (EarthInfo, 1995). The hourly data were used to determine 3,6 , and 24-hour rainfall for overlapping intervals beginning with each hour in the station's record. The results were used to create files of annual maximum 15-minute rainfall values for the three cooperative stations and annual maximum 1, 3, 6, and 24-hour rainfall values for each of the eight NWS and cooperative stations.

The NCDC rainfall data were recorded over a fixed hourly interval that begins on the hour. Since the true maximum rainfall in a given year may occur over a period which overlaps the fixed interval, empirical factors are used to convert the fixed interval maxima to an estimated 'true' interval value (Miller, 1982). These adjustment factors are summarized in Table XVI.

Rainfall data is collected at SRS from a network of eight rain gauges. These gauges are read once daily, usually around 6 a.m.. The daily rainfall measurements are reported to ATG and entered into an electronic data base. Rain gauge stations used in this study are summarized in Table XV and Figure 3. Files of annual maxima rainfall for each of the four stations were used in the statistical model. The annual maxima of daily rainfall were adjusted by the conversion factor in Table XVI to approximate true 24-hour maxima.

Model

An extreme-value distribution was assumed for each pe- riod of yearly maximum rainfall. Depending on the time period for the maximum rainfall, each maximum was multiplied by the appropriate factors found in Table XVI. After multiplying the rainfall by the appropriate factor, the maximum was obtained for each station and year. The average, standard deviation, and coefficient of variation of the yearly maximum rainfall were calculated. The individual maximum rainfall amounts for each station were standardized and used to fit a generalized extreme-value distribution.

Let $\mathrm{X}_{\mathrm{ij}}$ be the $\mathrm{i}^{\text {th }}$ yearly maximum rainfall for the appropriate time period for station- $\mathrm{j}$, then the mean, standard deviation, coefficient of variation (divided by $100 \%$ ), and standardized $i j^{\text {th }}$ value are given by:

$$
\overline{\mathrm{X}}_{\mathrm{j}}=\sum_{\mathrm{i}=1}^{\mathrm{n}_{\mathbf{j}}} \mathrm{X}_{\mathrm{ij}} / \mathrm{n}_{\mathrm{j}}
$$

$s_{j}=\sqrt{\sum_{i=1}^{n_{j}}\left(x_{i j}-\bar{X}_{j}\right)^{2} /\left(n_{j}-1\right)}$

$$
\begin{gathered}
\tau_{i j}=\frac{X_{i j}-\bar{X}_{j}}{S_{j}} \\
C V_{j}=S_{j} / \bar{X}_{j}
\end{gathered}
$$

Table XVII gives the average, the standard deviation, and the coefficient of variation divided by $100 \%$ for each time period and station. Also included for the rainfall time peri-

Table XVI. Multiplication Factors for Yearly Maximum by Rainfall Periods

\begin{tabular}{|lll|}
\hline $\begin{array}{l}\text { Rainfall } \\
\text { Period }\end{array}$ & $\begin{array}{l}\text { Multiplication } \\
\text { Factor }\end{array}$ & Comments \\
\hline 24-hour & 1.01 & except SRS datasets which used a fixed 24-hour period \\
& 1.13 & SRS data (Barricades 3 and 5, F200 area, and SRTC) \\
12-hour & 1.01 & \\
6-hour & 1.02 & \\
3-hour & 1.03 & \\
1-hour & 1.13 & \\
1.5 min. & 1.13 \\
\hline
\end{tabular}




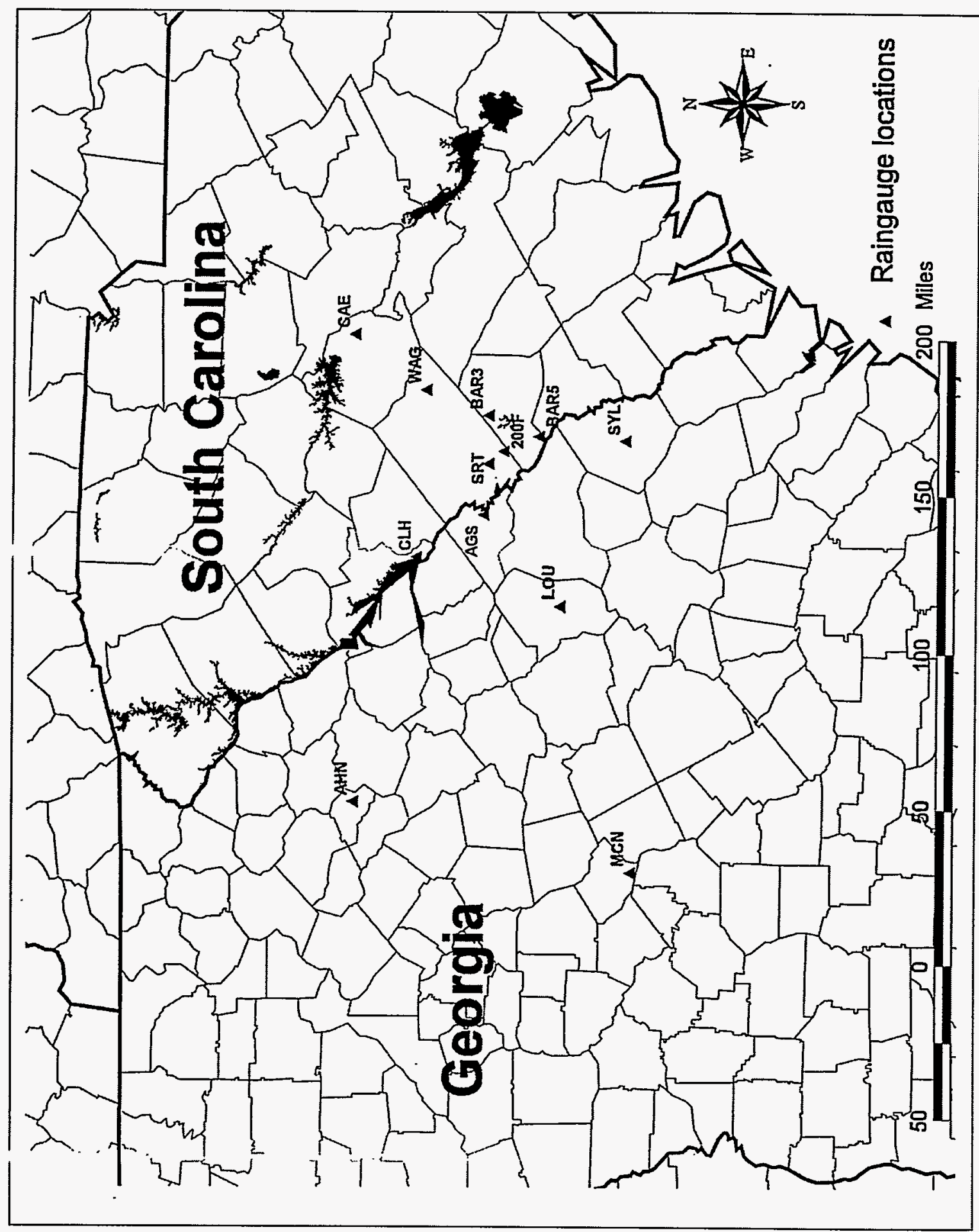

Figure 3. Rain Gauge Locations 
Table XVII. Station Average, Standard Deviation, and Coefficient of Variation for Maximum Yearly Rainfall by Rainfall Periods

\begin{tabular}{|c|c|c|c|c|}
\hline Station & $\begin{array}{l}\text { No. } \\
\text { Years }\end{array}$ & $\begin{array}{l}\text { Station } \\
\text { Average } \\
\text { (in.) }\end{array}$ & $\begin{array}{l}\text { Standard } \\
\text { Deviation } \\
\text { (in.) }\end{array}$ & $\begin{array}{l}\text { Coefficient } \\
\text { Variation } \\
(100 \%)\end{array}$ \\
\hline \multicolumn{5}{|c|}{ Time Period = 24-hour } \\
\hline Augusta & 48 & 3.44031 & 1.18761 & 0.345204 \\
\hline Athens & 38 & 3.98817 & 1.57366 & 0.394583 \\
\hline Barricade 3 & 35 & 3.43585 & 1.04429 & 0.303941 \\
\hline Barricade 5 & 29 & 3.77732 & 1.47263 & 0.389862 \\
\hline Clarks Hill & 42 & 3.74854 & 1.57028 & 0.418905 \\
\hline Columbia & 46 & 3.76752 & 1.17674 & 0.312338 \\
\hline F200 Area & 38 & 3.72246 & 1.13109 & 0.303856 \\
\hline Lotisville & 48 & 3,52700 & 1.12546 & 0.319099 \\
\hline Macon & 47 & 3.66802 & 1.41511 & 0.385797 \\
\hline SRTC & 31 & 3.84273 & 1.22965 & 0.319994 \\
\hline Sylyania & 48 & 3.50596 & 1.04634 & 0.298445 \\
\hline Wagner & 47 & 3.51459 & 1.30400 & 0.371025 \\
\hline \multicolumn{5}{|c|}{$\begin{array}{l}\text { Average wh. coefficient of variation }(100 \%)=0.34636 \\
\text { Shape Parameter: } \text { khat }=-0.12149 \\
\text { Z-Test: kratio }=-3.60874\end{array}$} \\
\hline
\end{tabular}

\begin{tabular}{|lllll|}
\hline Station & $\begin{array}{l}\text { No. } \\
\text { Years }\end{array}$ & $\begin{array}{l}\text { Station } \\
\text { Average } \\
\text { (in.) }\end{array}$ & $\begin{array}{l}\text { Standard } \\
\text { Deviation } \\
\text { (in.) }\end{array}$ & $\begin{array}{l}\text { Coefficient } \\
\text { Variation } \\
(1100 \%)\end{array}$ \\
\hline Time Period = 12-hour & & & \\
Augusta & 48 & 3.09691 & 1.07108 & 0.345854 \\
Athens & 38 & 3.34788 & 1.47808 & 0.441498 \\
Clarks Hill & 42 & 3.19665 & 1.49854 & 0.468786 \\
Columbia & 46 & 3.23661 & 1.05927 & 0.327278 \\
Louisville & 47 & 3.05020 & 1.17514 & 0.385266 \\
Macon & 47 & 3.20342 & 1.11145 & 0.346957 \\
Sylyania & 46 & $3.12419 \%$ & 0.88503 & 0.283282 \\
Wagner & 45 & 3.11888 & 1.10452 & 0.354141 \\
& & & \\
Average wt, coefficient of variation $(1100 \%)=0.366241$ \\
Shape Parameter; khat $=-0.15685$ \\
Z-Test: kratio $=-3.95960$
\end{tabular}


Table XVII. Station Average, Standard Deviation, and Coefficient of Variation for Maximum Yearly Rainfall by Rainfall Periods (contd)

\begin{tabular}{|c|c|c|c|c|}
\hline Station & $\begin{array}{l}\text { No. } \\
\text { Years }\end{array}$ & $\begin{array}{l}\text { Station } \\
\text { Average } \\
\text { (in.) }\end{array}$ & $\begin{array}{l}\text { Standard } \\
\text { Deviation } \\
\text { (in.) }\end{array}$ & $\begin{array}{l}\text { Coefficient } \\
\text { Variation } \\
(1100 \%)\end{array}$ \\
\hline \multicolumn{5}{|c|}{ Time Period $=$ 6-hour } \\
\hline Augusta & 48 & 2.62969 & 0.78791 & 0.299620 \\
\hline Athens & 38 & 2.72582 & 1.09917 & 0.403243 \\
\hline Clarks Hill & 40 & 2.64869 & 1.19490 & 0.451130 \\
\hline Columbia & 46 & 2.78017 & 0.95047 & 0.341875 \\
\hline Louisville & 46 & 2.67151 & 1.06892 & 0.400117 \\
\hline Macon & 47 & 2,85622 & 0.96548 & 0.338028 \\
\hline Sylyania & 41 & 2.69529 & 0.65149 & 0.241716 \\
\hline Wagner & 43 & 1.75020 & 0,99645 & 0,362317 \\
\hline \multicolumn{5}{|c|}{$\begin{array}{l}\text { Average wt. coefficient of variation }(100 \%)=0.35314 \\
\text { Shape Parameter; khat }=-0.13380 \\
\text { Z- Test: kratio }=-3.33043\end{array}$} \\
\hline
\end{tabular}

\begin{tabular}{|c|c|c|c|c|}
\hline Station & $\begin{array}{l}\text { No. } \\
\text { Years }\end{array}$ & $\begin{array}{l}\text { Station } \\
\text { Average } \\
\text { (in.) }\end{array}$ & $\begin{array}{l}\text { Standard } \\
\text { Deviation } \\
\text { (in.) }\end{array}$ & $\begin{array}{l}\text { Coefficient } \\
\text { Variation } \\
(\mathbf{1 1 0 0 \%})\end{array}$ \\
\hline \multicolumn{5}{|c|}{ Time Period = 3-hour } \\
\hline Augusta & 46 & 2.31616 & 0.80537 & 0,347718 \\
\hline Athens & 38 & 2.25733 & 0.80819 & 0.358032 \\
\hline Clarks Hill & 39 & 2.26732 & 0.92495 & 0.407949 \\
\hline Columbia & 42 & 2.48034 & 0,82606 & 0.333043 \\
\hline Louisville & 46 & 2.26175 & 0.87645 & 0.387512 \\
\hline Macon & 46 & 2.40080 & $0.78833^{\circ}$ & 0.328362 \\
\hline Sylvania & 40 & 2.36514 & 0.64097 & 0.271006 \\
\hline Wagner & 43 & 2.43415 & 0.89049 & 0.365833 \\
\hline \multicolumn{5}{|c|}{$\begin{array}{l}\text { Average wt. caefficient of variation }(1100 \%)=0.3500 \\
\text { Shape Paramefer: khat }=-0.10950\end{array}$} \\
\hline \multicolumn{5}{|c|}{ Z-Test: $\quad$ kratio $=-2.69009$} \\
\hline
\end{tabular}


Table XVII. Station Average, Standard Deviation, and Coefficient of Variation for Maximum Yearly Rainfall by Rainfall Periods (contd)

\begin{tabular}{|lllll|}
\hline Station & $\begin{array}{l}\text { No. } \\
\text { Years }\end{array}$ & $\begin{array}{l}\text { Station- } \\
\text { Average } \\
\text { (in.) }\end{array}$ & $\begin{array}{l}\text { Standard } \\
\text { Deviation } \\
\text { (in.) }\end{array}$ & $\begin{array}{l}\text { Coefficient } \\
\text { Variation } \\
(1100 \%)\end{array}$ \\
\hline Time Period = 1-hour & & & \\
& & & & \\
Augusta & 46 & 1.80038 & 0.65007 & 0.361073 \\
Athens & 35 & 1.57328 & 0.37792 & 0.240213 \\
Clarks Hill & 36 & 1.75746 & 0.61179 & 0.348110 \\
Columbia & 42 & 1.92181 & 0.57630 & 0.299877 \\
Florence & 16 & 1.87863 & 1.09706 & 0.583971 \\
Louisville & 40 & 1.92015 & 0.72830 & 0.379295 \\
Macon & 46 & 1.76722 & 0.65436 & 0.370277 \\
Sylvania & 34 & 1.80468 & 0.52970 & 0.293515 \\
Wagner & 39 & 1.95867 & 0.75274 & 0.384314 \\
& & & \\
Average vt. coefficient of yariation $(1100 \%)=0.348919$ \\
Shape Parameter: khat =-0.015450 & \\
Z-Test: kratio=0.37622 & & \\
\hline
\end{tabular}

\begin{tabular}{|lllll|}
\hline Station & $\begin{array}{l}\text { No. } \\
\text { Years }\end{array}$ & $\begin{array}{l}\text { Station } \\
\text { Average } \\
\text { (in.) }\end{array}$ & $\begin{array}{l}\text { Standard } \\
\text { Deviation } \\
\text { (in.) }\end{array}$ & $\begin{array}{l}\text { Coefficient } \\
\text { Variation } \\
(/ 100 \%)\end{array}$ \\
\hline Time Period $=15$ min. & & \\
Louisville & 25 & 0.97180 & 0.24411 & 0.251191 \\
Sylvania & 25 & 1.14356 & 0.36952 & 0.323129 \\
Wagner & 25 & 1.05768 & 0.29337 & 0.277367 \\
Average wt. coefficient of variation $(/ 100 \%)=0.28390$ \\
Shape Parameter khat $=0.15823$ \\
ZTest: kratio $=1.82577$ \\
\end{tabular}


ods is the generalized extreme value shape parameter and the Z-test (to determine if the shape parameter is statistically different from zero).

The standardized variables, $\tau_{i j}$, were used to fit a generalized extreme-value distribution to determine which extreme type distribution was appropriate. A single form of the three possible types of limiting distributions for extreme values has been derived by Fisher and Tippett (1928) and can be modeled by

$F(\tau)=\exp \left[-\{1-\mathrm{k}(\tau-\xi) / \alpha\}^{1 / k}\right], k \neq 0$,

$F(\tau)=\exp [-\exp [-(\tau-\xi) / \alpha\}], \mathrm{k}=0$.

$\tau$ is bounded by $\xi+\alpha / k$ from above if $k>0$ and from below if $k<0$. Here $\xi$ and $\alpha$ are location and scale parameters, respectively. The shape parameter, $k$, determines which extreme-value distribution is best represented by the data. Fisher-TippetI Types I, II, and III correspond to $k=0, k<0$, and $k>0$, respectively. In practice the shape parameter usually lies in the range $-(1 / 2)<k<(1 / 2)$. When this is the case, the following can be used to estimate the parameters, $\xi, \alpha$, and $k$ (Hosking, et al., 1985):

$\hat{k}=7.8590 c+2.9554 c^{2}$, where

$c=\frac{2 b_{1}-b_{0}}{3 b_{2}-b_{0}}-\frac{\log 2}{\log 3}$

The error in estimating $\mathrm{k}$ using Eq. (39) is less than 0.0009 through the range $-(1 / 2)<\mathrm{k}<(1 / 2)$.

Given $\hat{k}$ the scale and location parameters can be estimated successively by

$\hat{\alpha}=\frac{\left(2 b_{1}-b_{0}\right) \hat{k}}{\Gamma(1+\hat{k})\left(1-2^{-k}\right)}$
$\hat{\xi}=b_{0}+\hat{\alpha}\{\Gamma(1+\hat{k})-1\} \hat{\hat{k}}$

The Type I extreme-value distribution, or Gumbel distribution, is a particularly simple special case of the generalized extreme-value (GEV) distribution and is often useful to test whether a given set of data is generated by a Gumbel rather than a GEV distribution. This process is equivalent to testing whether the shape parameter, $k$, is zero in the GEV distribution. Assuming the null hypothesis $\mathrm{H}_{0}: \mathrm{k}=0$, the estimator $\hat{\mathrm{k}}$ is asymptotically distributed as $\mathrm{N}(0,0.5633$ / $\mathrm{n})$. The test may be performed by comparing the statistic $\mathrm{Z}$ $=\hat{\mathrm{k}}(\mathrm{n} / 0.5633)^{1 / 2}$ with the critical values of a standard normal distribution. Significant positive values of $Z$ imply rejection of $\mathrm{H}_{\mathrm{o}}$ in favor of the alternative $\mathrm{k}>0$, and significant negative values of $Z$ imply rejection in favor of $k<0$. Values of $Z$ (k-ratio) between -1.96 and +1.96 indicate that $k$ is not significantly different from zero with $95 \%$ confidence.

The estimates of $\hat{\mathbf{k}}$ and the Z-statistic ratio (kratio) are given in Table XVIII for all rainfall periods analyzed. Only the 15-minute and 1-hour rainfall periods have a zero shape parameter indicating a Type I extreme value distribution. For all other rainfall periods, the shape parameter is negative indicating a Type II extreme value distribution.

For the Type I or Gumbel distribution, the scale and location parameters can be estimated using the Method of Moments (Eliasson, 1997). These estimates are given by

$\hat{\alpha}=1 / 1.28255$

$\hat{\xi} / \hat{\alpha}=\hat{\beta}=0.57722$.

The estimates of scale and location parameters for the Type II extreme value distribution are given in Eqs. (40) and (41), where the values $b_{e}, b_{1}$, and $b_{2}$ are estimated from the data using Eqs. (43) through (45). $\tau_{\mathrm{ij}}$ are the standardized variables ordered from smallest to largest and ij is the rank.

Table XVIII. Scale and Location Parameters for Type II GEV by Rainfall Periods

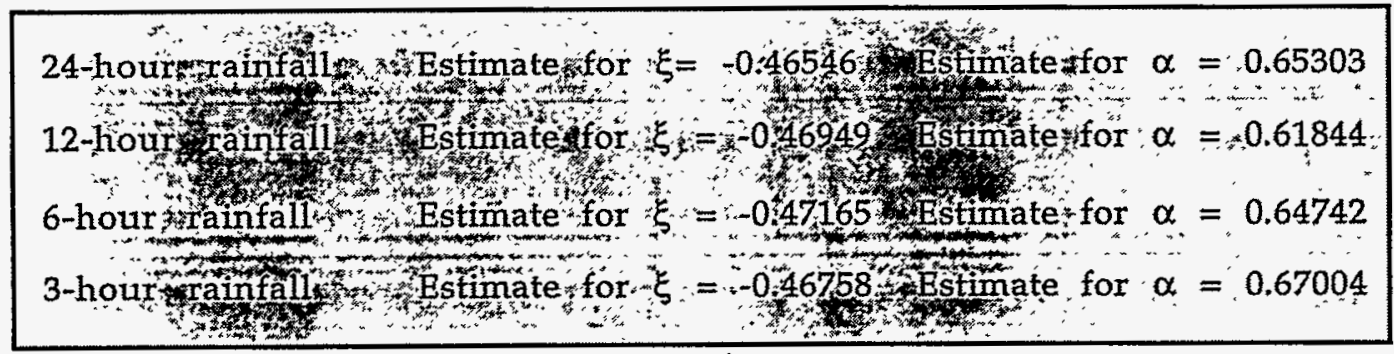


$b_{0}=\sum_{i j=1}^{N} \tau_{i j}+N$

$b_{1}=\frac{1}{N(N-1)} \sum_{i j=1}^{N}(i j-1) \tau_{i j}$

$h_{2}=\frac{1}{N(N-1)(N-2)} \sum_{i j=1}^{N}(i j-1)(i j-2) \tau_{i j}$

In order to determine the rainfall amount, $\tau$ in Eqs. (37) for the Type II distribution and Eq. (38) for the Type I distribution must be solved for each return period of interest. Each station will have a separate rainfall amount for each return period.

For the Type I distributions, rainfall for the 15-minute and 1-hour periods, Eq. (38) is used.

Let $P$ be the return period of interest. Then (1-1/P) is the probability corresponding to a rainfall amount $\geq \operatorname{Inch}_{p}$ or

$\operatorname{Prob}\left(\operatorname{Inch} \geq \operatorname{Inch}_{\mathrm{p}}\right)=(1-1 / \mathrm{P})=$ $\exp \left[-\left\{\exp \left[-\left(1.28255\left(\tau_{p}\right)+0.5772\right)\right]\right\}\right]$,

where

$\tau_{p}=\left(X_{p}-\bar{X}_{j}\right) / S_{j}$

The station average, $\overline{\mathrm{X}}_{\mathbf{j}}$, and the station standard deviaLion, $S_{\text {, }}$, are computed from Eqs. (32) and (33). The return period is then given by Eq. (47).

$$
\begin{aligned}
X_{p}= & S_{j}(\log [-\log \{-(1-1 / P)\}]-0.57722) \\
& (1 / 1.28255)+\bar{X}_{j} .
\end{aligned}
$$

Eliasson (1997) indicates that often a smoother fit can be obtained by using the coefficient of variation averaged over all stations. Eliasson also gives an alternate method to Eq. (48) using the 5-year-return rainfall, which should always be within the data. Both Eq. (48) and Eq. (49) in which the individual station's $\mathrm{CV}_{\mathrm{j}}$ and the 5-year return rainfall, denoted by $M 5_{j}$, can be used to obtain the rainfall for station $j$ and return period $P$.

$\mathrm{X}_{\mathrm{p}}=\mathrm{M} 5_{\mathrm{j}}\left[1+\mathrm{C}_{\mathrm{i}}(\mathrm{y}-1.5]\right.$.

where $y=\log (-\log (1(1-1 / P)))$,

$M 5_{j}=S_{j}\{(0.8-0.57722) / 1.28255\}+X_{j}$,

and

$C_{i}=0.78 /\left\{\left(1 / C V_{j}\right)+0.72\right\}$.

If the coefficient of variation is averaged over all stations, $\mathrm{C}_{\mathrm{a}}$ replaces $\mathrm{C}_{\mathrm{a}}$ in Eqs. (49) and (51), where $\mathrm{CV}_{\mathrm{a}}$ is the average coefficient of variation and $\mathrm{C}_{\mathrm{a}}$ is computed by

$\mathrm{C}_{\mathrm{a}}=0.78 /\left\{\left(1 / \mathrm{CV}_{\mathrm{a}}\right)+0.72\right\}$

The 24-hour, 12-hour, 6-hour, and 3-hour yearly maximum rainfall fit a Type- $\Pi$ extreme value distribution. The shape parameter, $k$, was given in Table XVII . The scale and location parameters are given in Table XVIII.

To get the rainfall amounts for each return period of interest, Eq. (37) must be solved for the station's standardized value, $\tau_{\mathrm{p}}$, and then converted to actual inches. Eq. (53) is used to get the rainfall in inches for each station for a return period of $P$ years.

$\mathrm{x}_{\mathrm{p}-\mathrm{j}}=\overline{\mathrm{X}}_{\mathrm{p}}+\mathrm{S}_{\mathrm{j}}\left\{\hat{\xi}+\left(\frac{\hat{\alpha}}{\hat{\mathrm{k}}}\right)\left(1-\left[-\log \left(1-\frac{1}{\mathrm{P}}\right)\right]^{\hat{\mathrm{k}}}\right)\right\}$.

\section{Results for Extreme Rainfall}

Extreme rainfall estimates for return periods from 10 to 100,000 years are summarized in Table XIX and plotted in Figure 4. 
Table XIX. Extreme Rainfall Estimates by Accumulation Period

\begin{tabular}{|cccccccc|}
\hline Return & Frequency & \multicolumn{5}{c|}{} \\
Period (yrs) & (per year) & \multicolumn{5}{c}{ Accumulation Period } \\
\cline { 3 - 7 } & & 15 -min & 1-hour & 3-hours & 6 hours & 24-hours \\
\hline 10 & $1 \times 10^{-4}$ & 1.5 & 2.7 & 3.3 & 3.7 & 5.0 \\
50 & $4 \times 10^{-2}$ & 1.8 & 3.2 & 4.0 & 4.4 & 6.1 \\
100 & $1 \times 10^{-2}$ & 2.1 & 3.9 & 5.1 & 5.7 & 7.8 \\
200 & $5 \times 10^{-3}$ & 2.3 & 4.2 & 5.8 & 6.4 & 8.8 \\
500 & $2 \times 10^{-3}$ & 2.6 & 4.7 & 6.7 & 7.4 & 10.3 \\
1000 & $1 \times 10^{-3}$ & 2.7 & 5.0 & 7.4 & 8.3 & 11.5 \\
2000 & $5 \times 10^{-4}$ & 2.9 & 5.4 & 8.2 & 9.2 & 12.8 \\
5000 & $2 \times 10^{-4}$ & 3.2 & 5.8 & 9.4 & 10.7 & 14.7 \\
10000 & $1 \times 10^{-4}$ & 3.3 & 6.2 & 10.3 & 11.8 & 16.3 \\
50000 & $2 \times 10^{-5}$ & 3.7 & 7.0 & 12.8 & 15.1 & 20.6 \\
100000 & $1 \times 10^{-5}$ & 3.9 & 7.4 & 14.1 & 16.7 & 22.7 \\
\hline
\end{tabular}




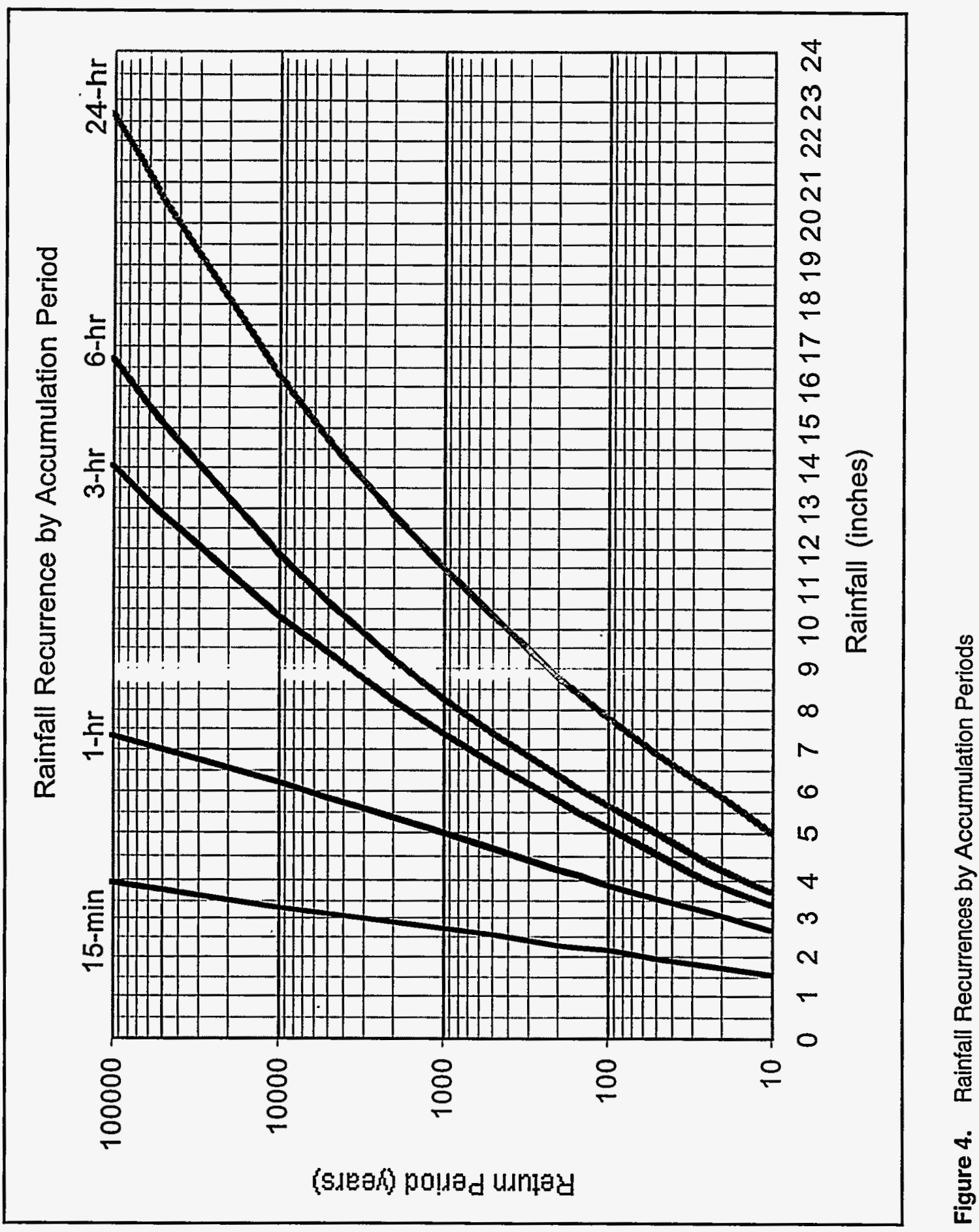




\section{Acknowledgments}

The work performed for this project was funded by the U. S. Department of Energy under Contract DE-AC0989SR18035.

\section{References}

EarthInfo, Inc., NCDC Hourly and 15 Minute Precipitation, Boulder, CO'(1995).

Eliasson, J., 1997: A Statistical Model for Extreme Precipitation, Water Resources Research, Vol. 33, No. 3, pp 449. 455 .

Fisher, R. A., and Tippett, L. H. C., 1928, "Limiting Forms of the Frequency Distribution of the Largest or Smallest Number of a Sample," Proc. Cambridge Phil. Soc.; 24, pp. 180-190.

Fujita, T. T., 1971: Proposed Characterization of Tornadoes and Hurricanes by Area and Intensity. Satellite and Mesometeorology Research Project Research Paper 91, Department of Geophysical Sciences, The University of Chicago, Chicago, IL. 44 pp.

Fujita, T. T., 1973: Experimental Classification of Tornadoes in FPP Scale. Satellite and Mesometeorology Research Project Research Paper 98, Department of Geophysical Sciences, The University of Chicago, Chicago, II. $15 \mathrm{pp}$.

Fujita, T. T., 1980: Tornado and High-Wind Hazards at Savannah River Plant. Task No. 1. Site-Specific Evaluation Performed for Lawrence Livermore Laboratory under P.O. No. 7249609.

Fujita, T. T., and Pearson, A. D., 1973: "Results of FPP Classification of 1971 and 1972 Tornadoes," Preprints of the Eighth Conference on Severe Local Storms, Denver, Co, published by the American Meteorological Society, Boston, MA.

Garrett, A. J., 1983: April 23, 1983 Tornado at the Savannah River Plant. DP-1667. E. I. Du Pont de Nemours and Company, Savannah River Laboratory, Aiken, SC 29808.

Hosking, J. R. M., J. R. Wallis, E. F. Wood, 1985: “Estimation of the Generalized Extreme-Value Distribution by the Method of Probability-Weighted Moments", Technometrics, August 1985, Vol. 27, No. pages 251-261.
Hunter, C. H., 1989: A Climatological Description of the Savannah River Site (U). WSRC-RP-89-313. Westinghouse Savannah River Company, Aiken, SC 29808.

Lu, D., 1995: A Statistically Rigorous Model For Tornado Hazard Assessment, Institute for Disaster Research, Master Thesis Texas Tech University.

Mehta, K. C., Minor, J. E., McDonald, J. R., Manning, B. R., Abernathy, J. J. and Koehler, U. W., 1975: "Engineering Aspects of the Tornadoes of April 3-4, 1974," report published by the National Academy of Sciences, Washington, DC.

McDonald, J. R., 1981: A Methodology for Tornado Hazard Probability Assessment, Prepared for Division of Health, Siting and Waste Management Office of Nuclear Regulatory Research, U. S. Nuclear Regulatory Commission, Washington, DC.

McDonald, J. R., 1985: Evaluation of SRP Buildings or Facilities for Effects of Tornadoes. McDonald, Mehta and Minor, Consulting Engineers, Lubbock, TX, 79409.

McDonald, J. R., 1997: Tornado Hazard Assessment of Facilities at the Savannah River Site. McDonald-Mehta Engineers, Lubbock, TX, 79409.

Miller, J. F., Engineering Meteorology, Elsevier Scientific Publishing Co., New York (1982).

Parker, M. J. and R. J. Kurzeja, 1990: October 1, 1989 Tornado at the SavannahRiver Site (U). WSRC-RP-89-1288. Westinghouse Savannah RiverCompany, Aiken, SC 29808.

Parker, M. J., 1991: Savannah River Site Tornado Damage of March 1991 (U). WSRC-RP-91-439. Westinghouse Savannah River Company, Aiken,SC 29808.

Pepper, D. W. and J. F. Schubert, 1978: Tornado Activity at SRP During 1976. DP-1451. E. I. Du Pont de Nemours and Company, Savannah River Laboratory, Aiken, SC 29808.

Plummer, G. and J. Purvis, 1991: Tornadoes in Georgia 1950-1989; Technical Paper \#110191, Southeast Regional Climate Center, Columbia, SC 29201; 28 pp.

Purvis, J. C., S. Sidlow, D. J. Smith, I. Turner, W. Tyler, 1990: South Carolina Tornado Statistics 1912-1989; Research Report \#121590, Southeast Regional Climate Center, Columbia, SC 29201; 59 pp.

Weber, J. H., 1998: Tornado, Maximum Wind Gust, and Extreme Rainfall Event Recurrrence Frequencies Calculation Note, SRT-SCS-98-050. 
Tornado, Maximum Wind Gust, and Extreme Rainfall Event

Recurrence Frequencies at the Savannah River Site

WSRC-TR-98-00329 


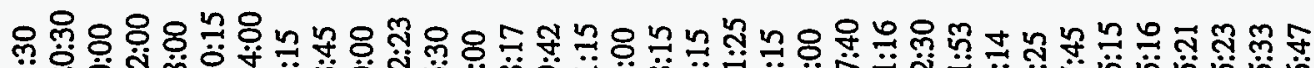

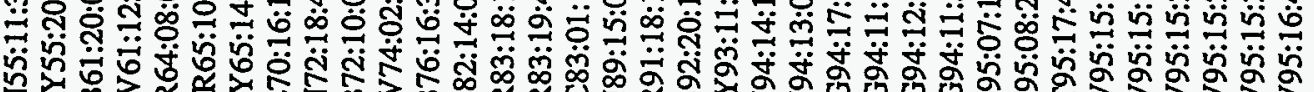

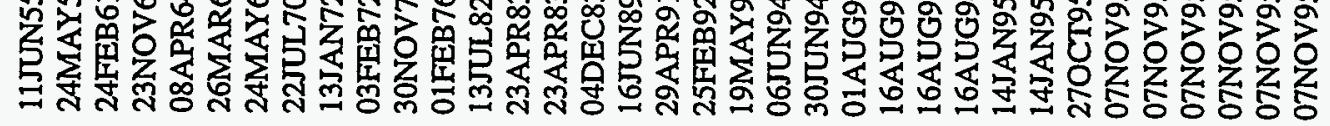

马

\section{急}

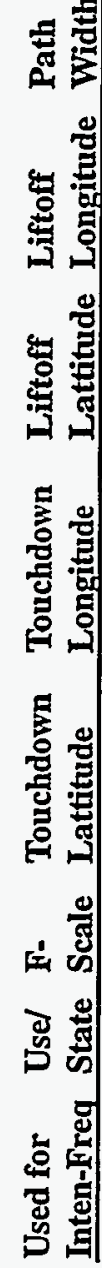

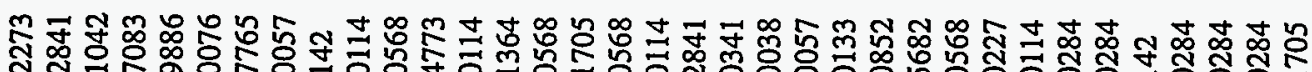

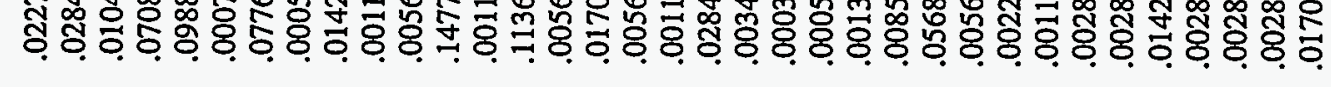

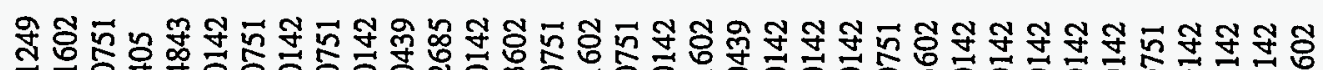

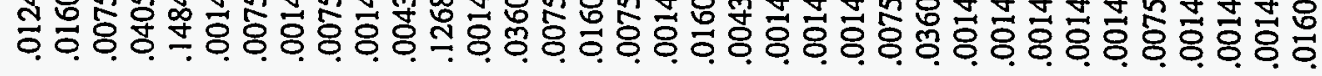
moำ

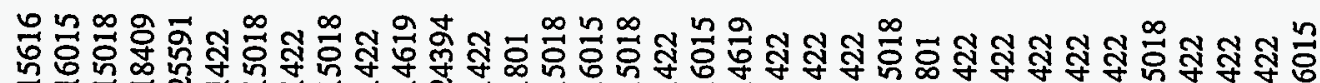

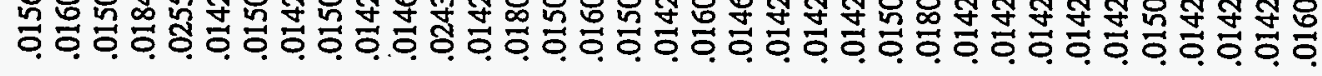

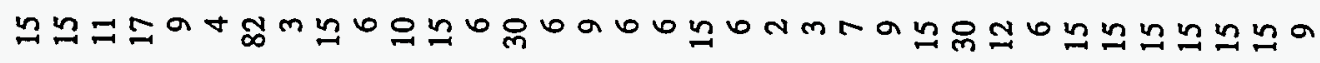

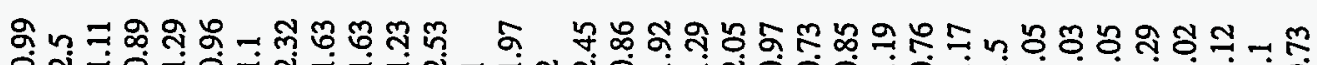

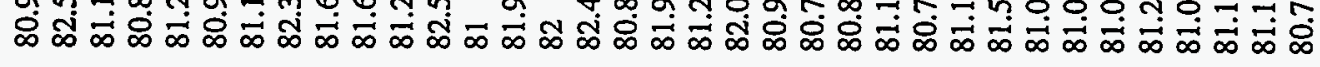

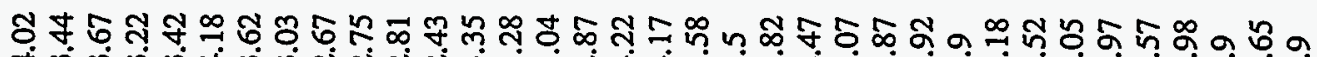

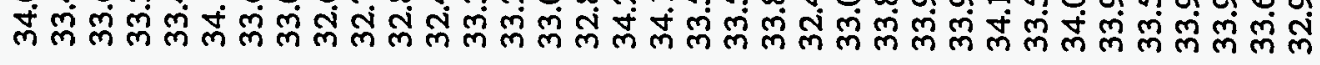

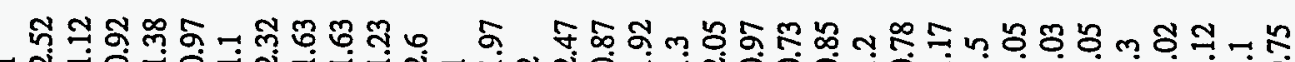
め

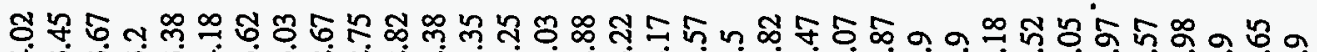

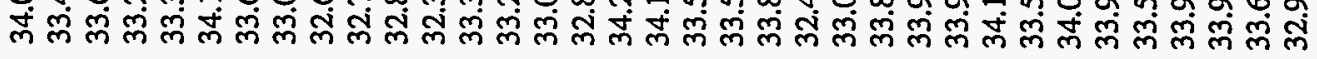
00000000000000000000000000000000000

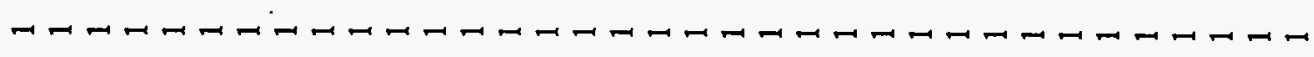

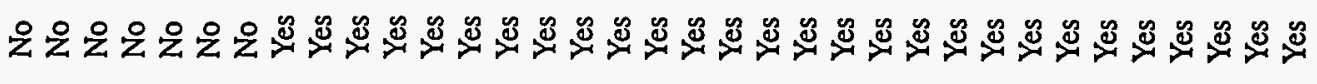




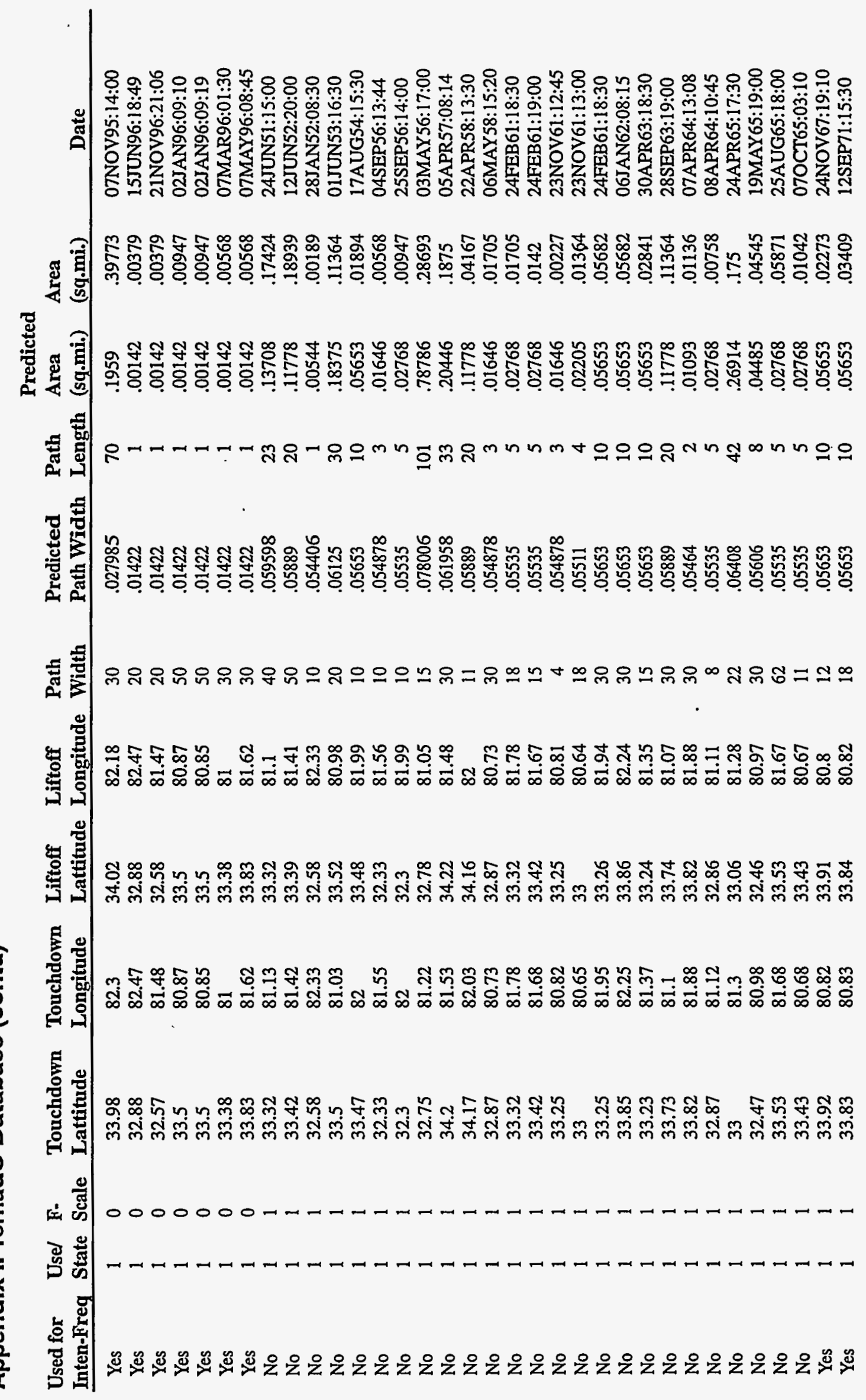




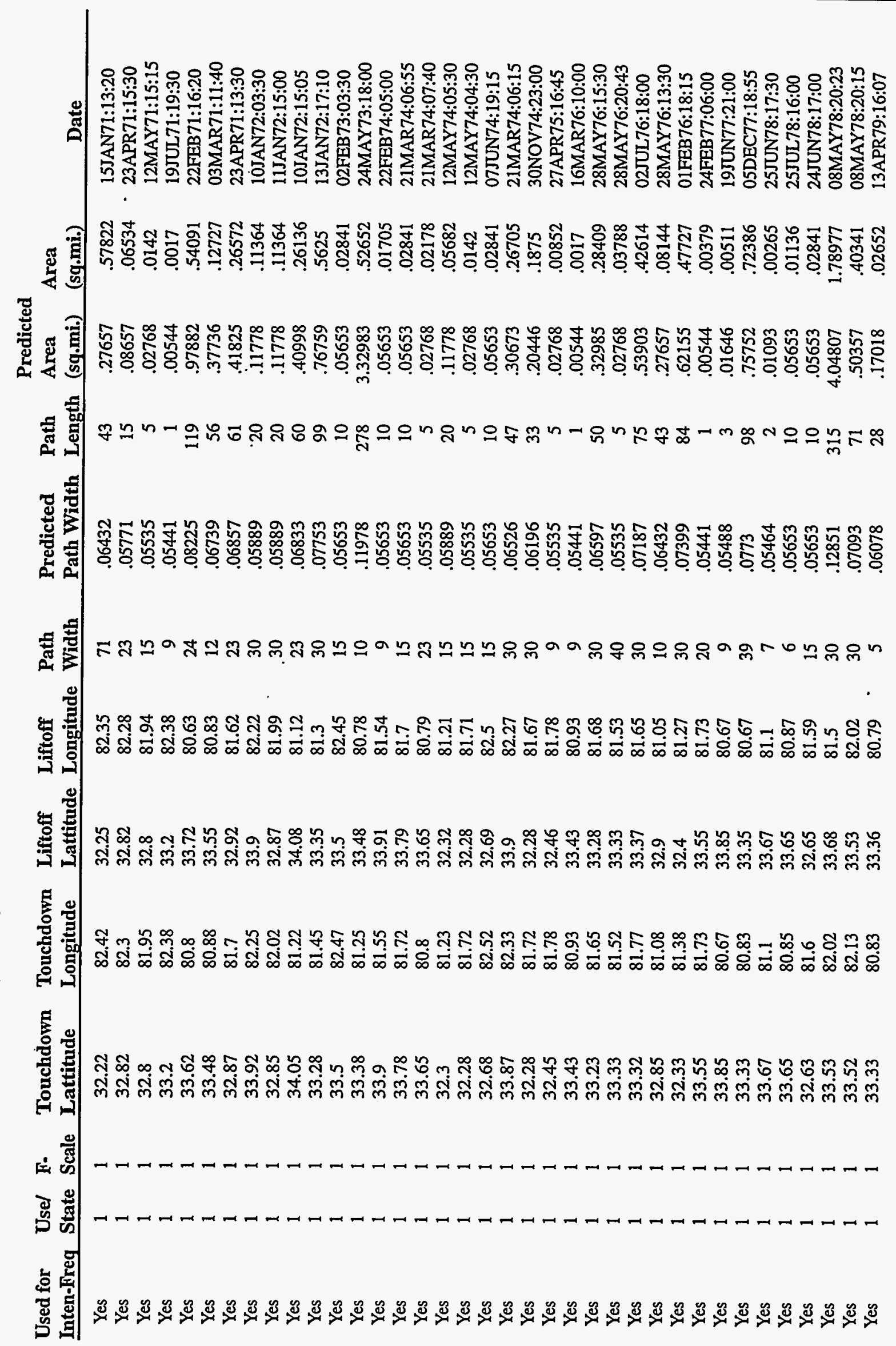




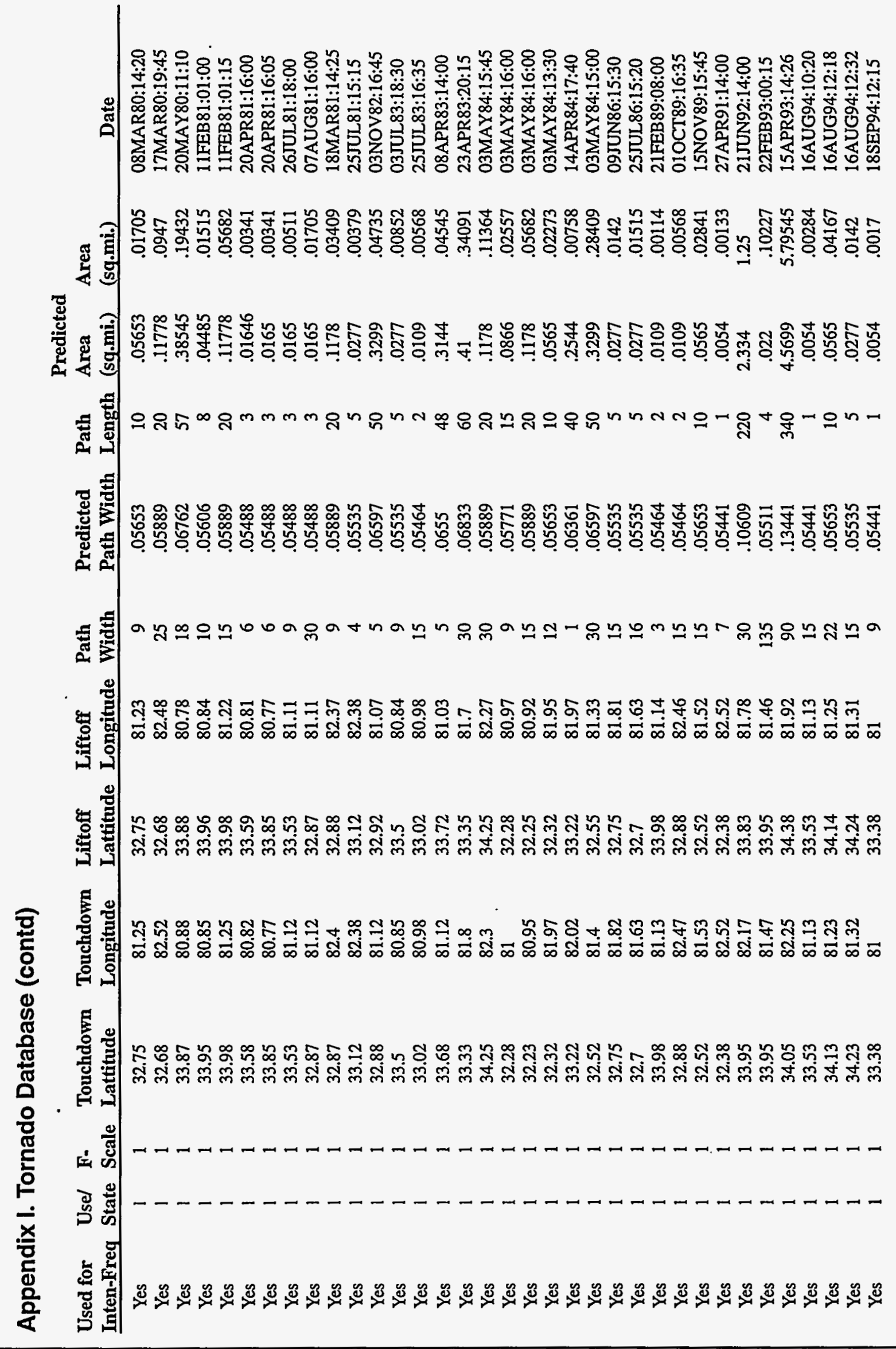




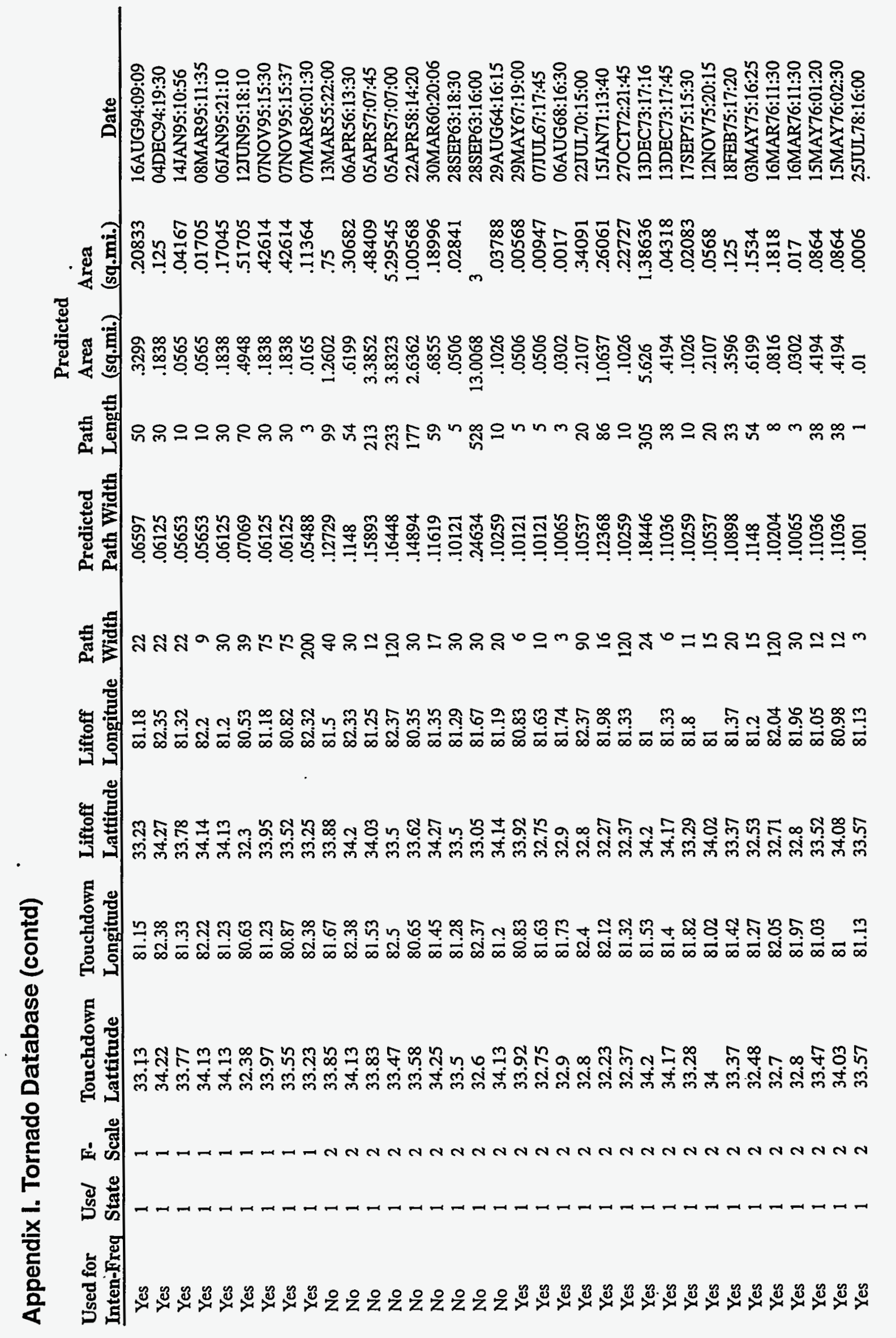




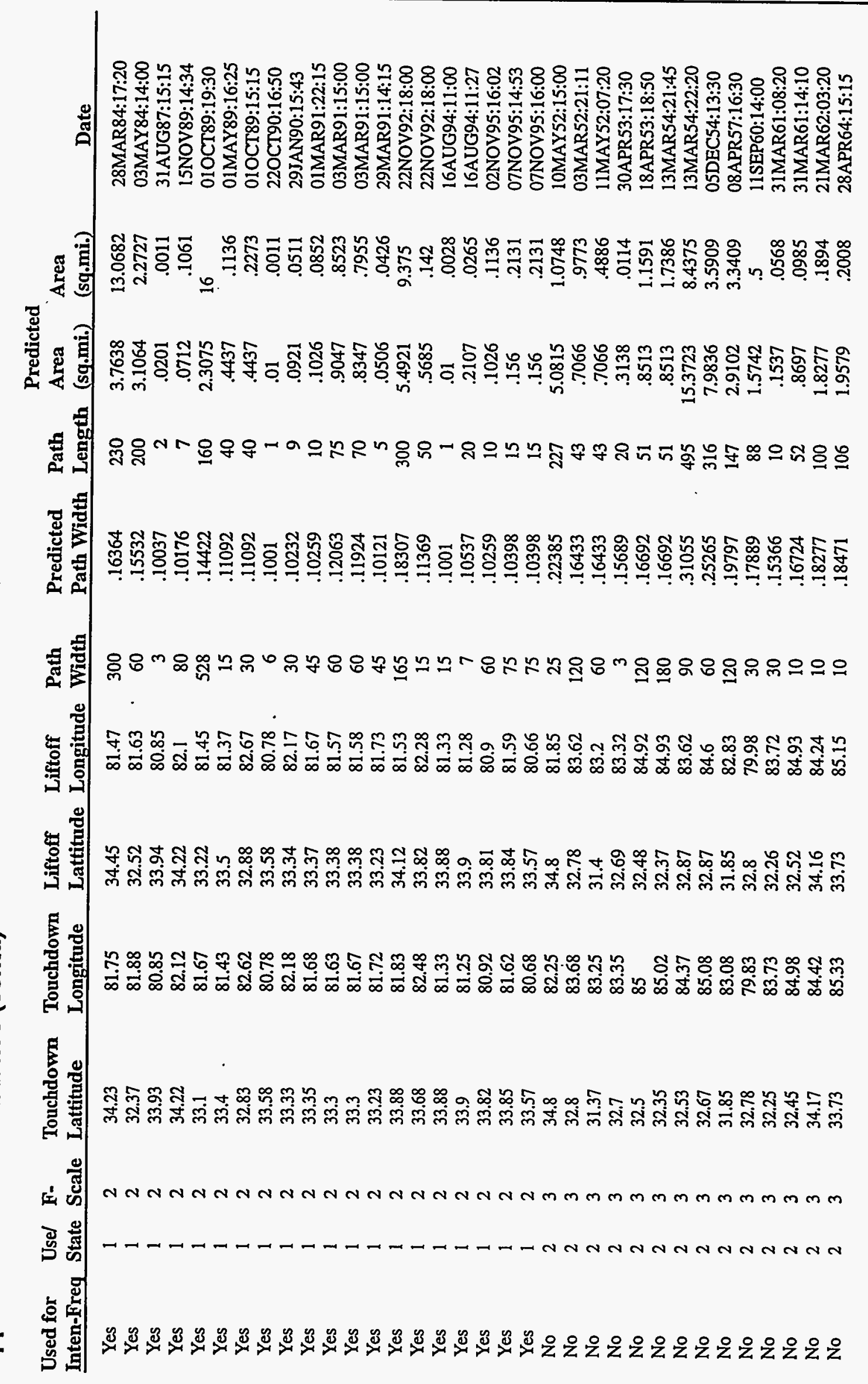




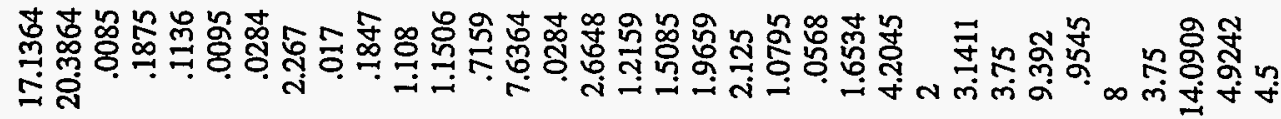

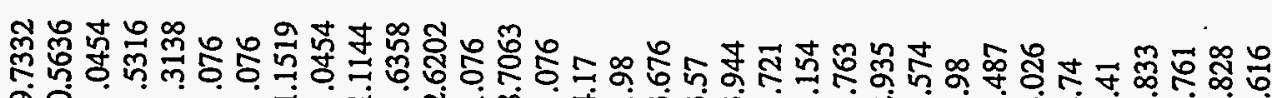
ล่

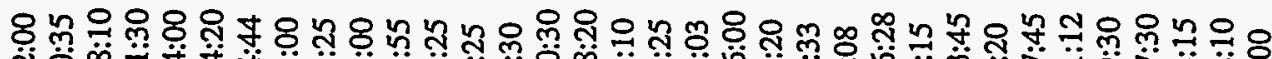

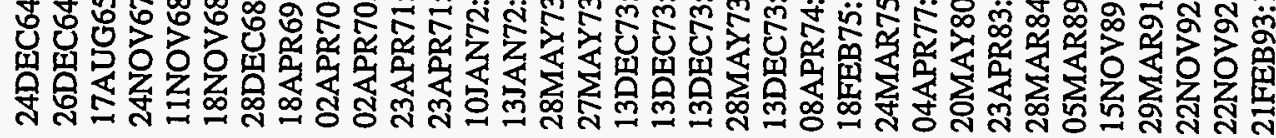

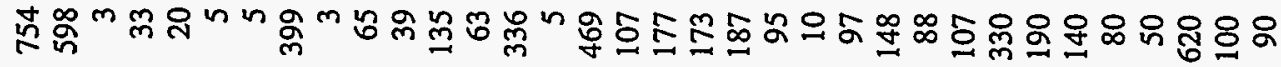

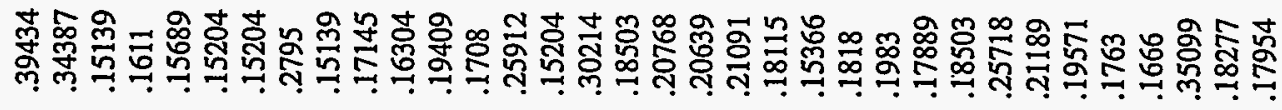

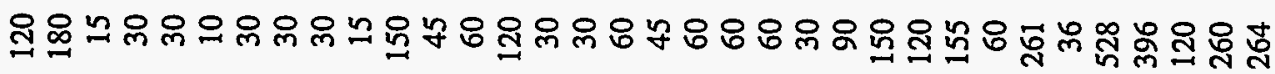

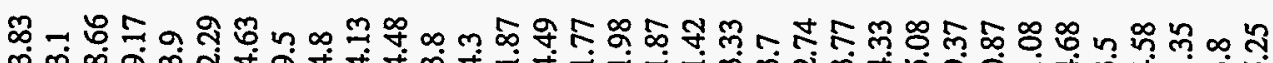

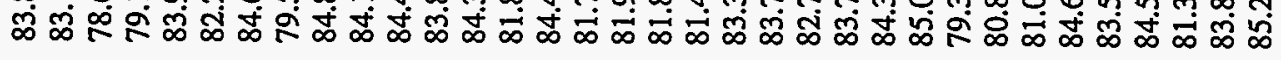

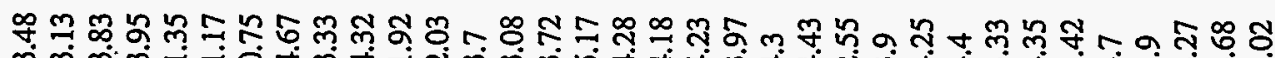

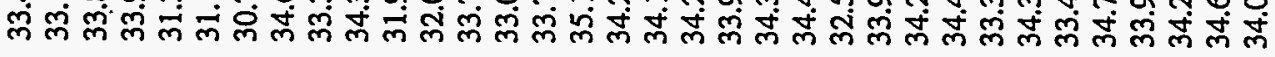

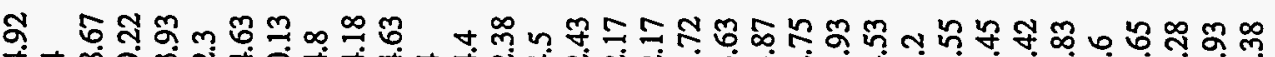

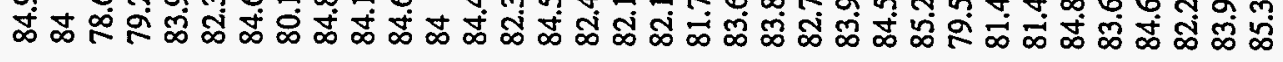

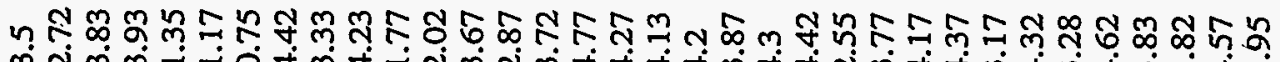

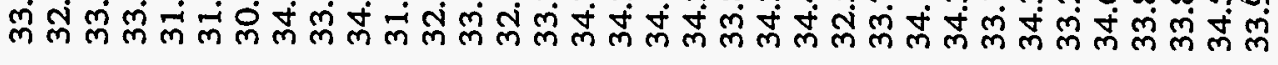

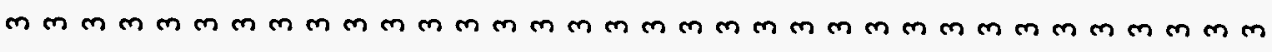

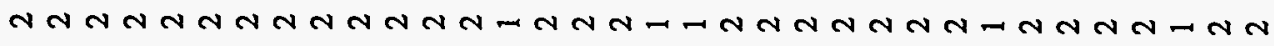

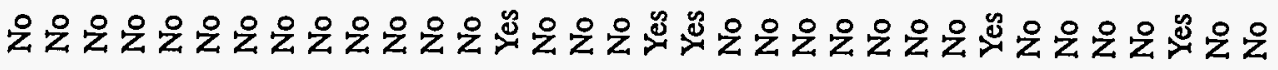




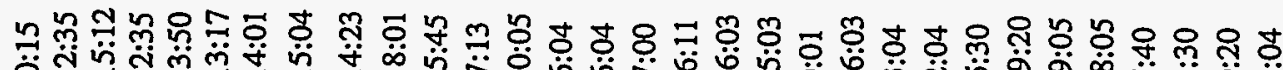

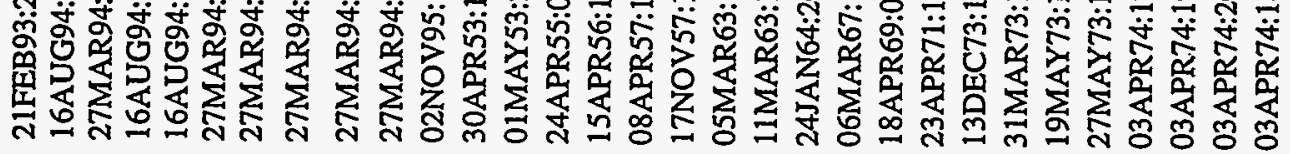

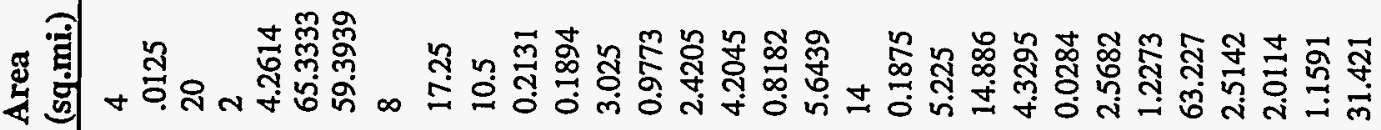

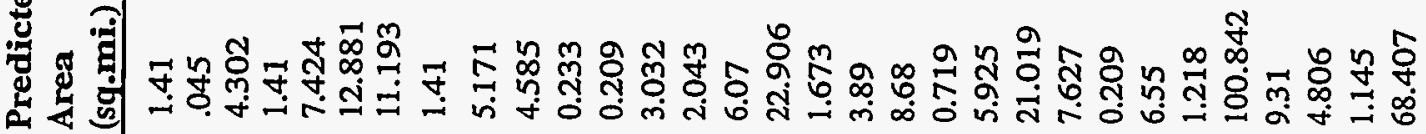

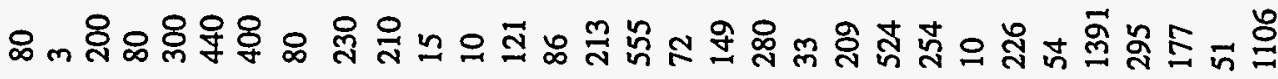

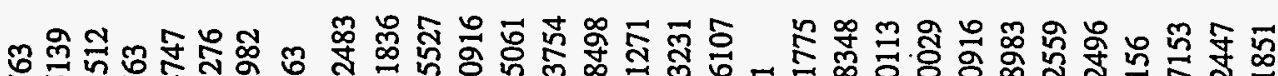

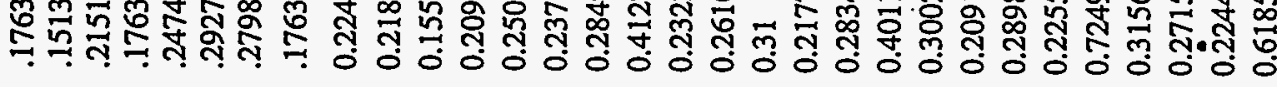

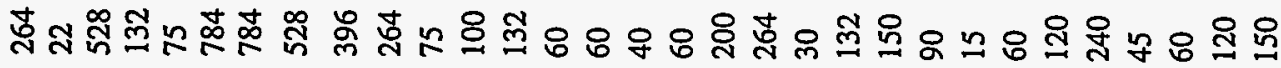

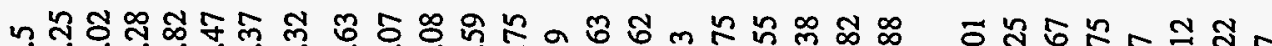

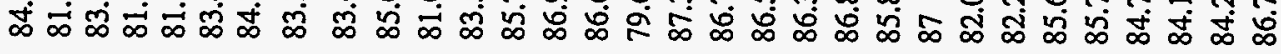

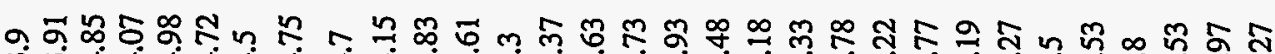
लं

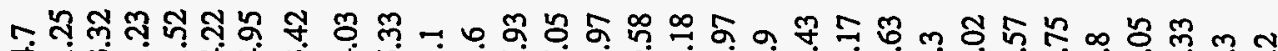
एं

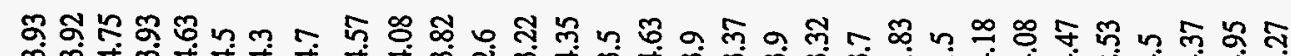

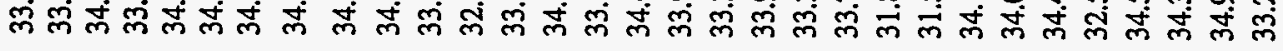

$m m m m m m m m m m m \forall \forall \forall \forall \forall+\forall \forall \forall \forall+\forall \forall \forall+\forall \forall \forall+\forall$

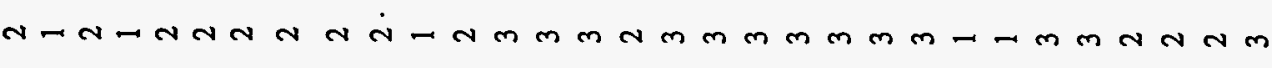

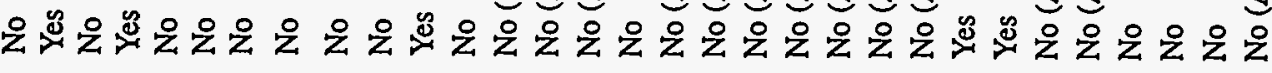




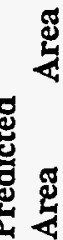

悹

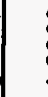

总

苗

m

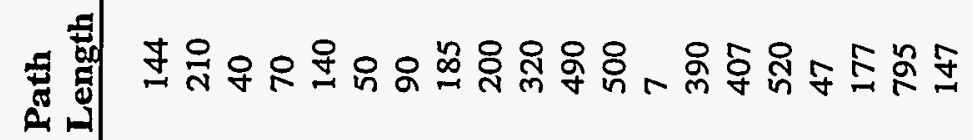

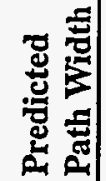

Е

串

氮

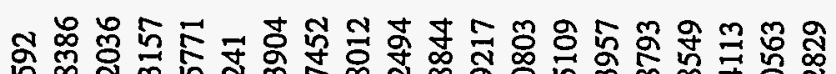

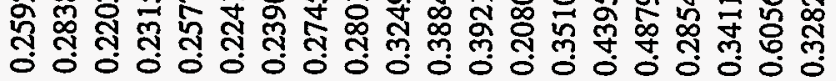

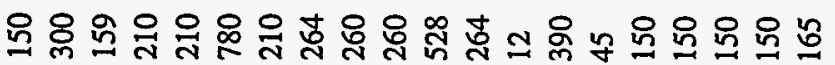

น ำ กิ ณ

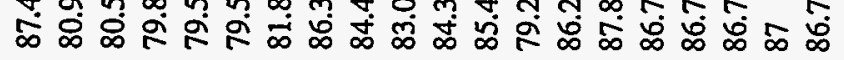

ศุ ษ

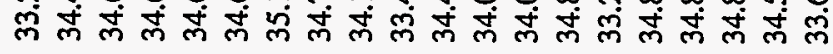

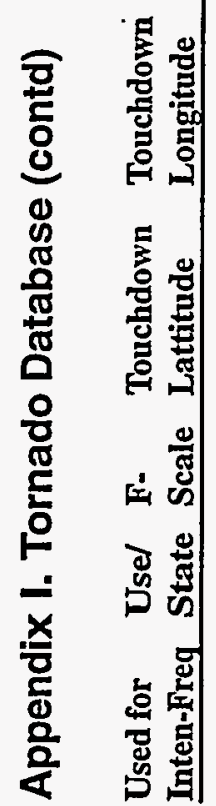

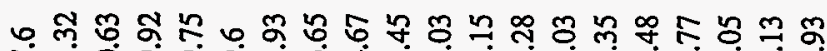

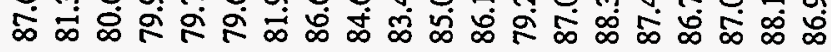

\%

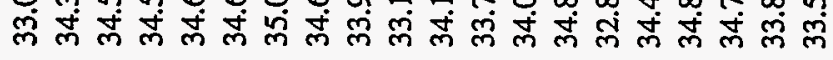

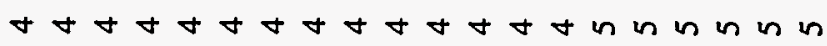

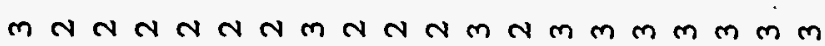

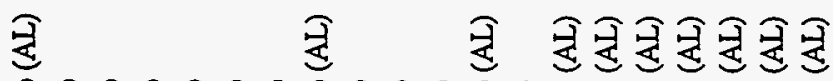

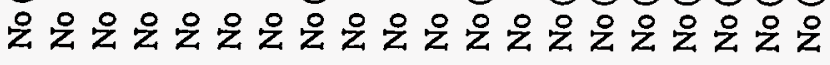

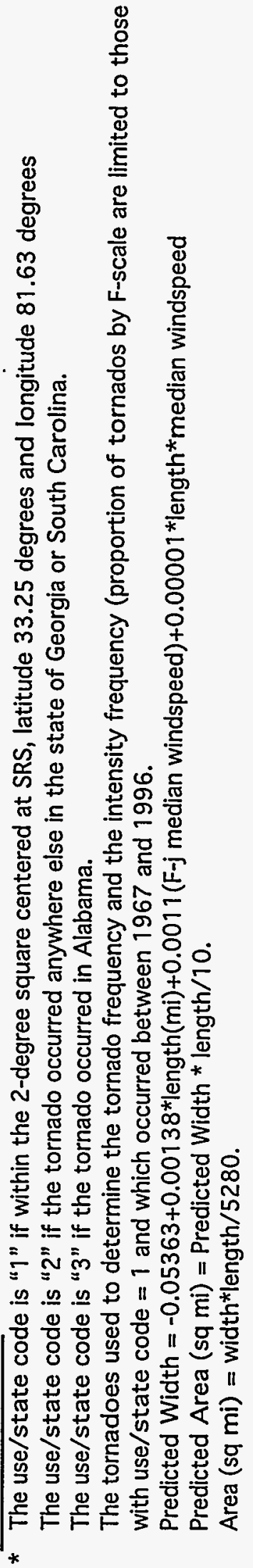




\section{Appendix II. Breakdown of Tornado Data}

Number of Tornadoes in two-degree square centered at SRS $\left(33.25^{\circ} \mathrm{N}, 81.63^{\circ} \mathrm{W}\right)$

\begin{tabular}{|c|c|c|c|c|c|c|c|}
\hline \multicolumn{8}{|c|}{ F-Scale } \\
\hline Year & F-0 & F-1 & $F-2$ & F-3 & $F-4$ & F-5 & Total \\
\hline 1951 & 0 & 1 & 0 & 0 & 0 & 0 & 1 \\
\hline 1952 & 0 & 2 & 0 & 0 & 0 & 0 & 2 \\
\hline 1953 & 0 & 1 & 0 & 0 & 0 & 0 & 1 \\
\hline 1954 & 0 & 1 & 0 & 0 & 0 & 0 & 1 \\
\hline 1955 & 2 & 0 & 1 & 0 & 0 & 0 & 3 \\
\hline 1956 & 0 & 3 & 1 & 0 & 0 & 0 & 4 \\
\hline 1957 & 0 & 1 & 2 & 0 & 0 & 0 & 3 \\
\hline 1958 & 0 & 2 & 1 & 0 & 0 & 0 & 3 \\
\hline 1959 & 0 & 0 & 0 & 0 & 0 & 0 & 0 \\
\hline 1960 & 0 & 0 & 1 & 0 & 0 & 0 & 1 \\
\hline 1961 & 2 & 5 & 0 & 0 & 0 & 0 & 7 \\
\hline 1962 & 0 & 1 & 0 & 0 & 0 & 0 & 1 \\
\hline 1963 & 0 & 2 & 2 & 0 & 0 & 0 & 4 \\
\hline 1964 & 1 & 2 & 1 & 0 & 0 & 0 & 4 \\
\hline 1965 & 2 & $4^{\circ}$ & 0 & 0 & 0 & 0 & 6 \\
\hline 1966 & 0 & 0 & 0 & 0 & 0 & 0 & 0 \\
\hline 1967 & 0 & 1 & 2 & 0 & 0 & 0 & 3 \\
\hline 1968 & 0 & 0 & 1 & 0 & 0 & 0 & 1 \\
\hline 1969 & 0 & 0 & 0 & 0 & 0 & 0 & 0 \\
\hline 1970 & 1 & 0 & 1 & 0 & 0 & 0 & 2 \\
\hline 1971 & 0 & 8 & 1 & 0 & 0 & 0 & 9 \\
\hline 1972 & 2 & 4 & 1 & 1 & 0 & 0 & 8 \\
\hline 1973 & 0 & 2 & 2 & 2 & 2 & 0 & 8 \\
\hline 1974 & 1 & 8 & 0 & 0 & 0 & 0 & 9 \\
\hline 1975 & 0 & 1 & 4 & 0 & 0 & 0 & 5 \\
\hline 1976 & 1 & 6 & 4 & 0 & 0 & 0 & 11 \\
\hline 1977 & 0 & 3 & 0 & 0 & 0 & 0 & 3 \\
\hline 1978 & 0 & 5 & 1 & 0 & 0 & 0 & 6 \\
\hline 1979 & 0 & 1 & 0 & 0 & 0 & 0 & 1 \\
\hline 1980 & 0 & 3 & 0 & 0 & 0 & 0 & 3 \\
\hline 1981 & 0 & 8 & 0 & 0 & 0 & 0 & 8 \\
\hline 1982 & 1 & 1 & 0 & 0 & 0 & 0 & 2 \\
\hline 1983 & 3 & 4 & 0 & 1 & 0 & 0 & 8 \\
\hline 1984 & 0 & 6 & 2 & 0 & 0 & 0 & 8 \\
\hline 1985 & 0 & 0 & 0 & 0 & 0 & 0 & 0 \\
\hline 1986 & 0 & 2 & 0 & 0 & 0 & 0 & 2 \\
\hline 1987 & 0 & 0 & 1 & 0 & 0 & 0 & 1 \\
\hline 1988 & 0 & 0 & 0 & 0 & 0 & 0 & 0 \\
\hline 1989 & 1 & 3 & 4 & 0 & 0 & 0 & 8 \\
\hline 1990 & 0 & 0 & 2 & 0 & 0 & 0 & 2 \\
\hline 1991 & 1 & 1 & 4 & 0 & 0 & 0 & 6 \\
\hline 1992 & 1 & 1 & 2 & 1 & 0 & 0 & 5 \\
\hline 1993 & 1 & 2 & 0 & 0 & 0 & 0 & 3 \\
\hline 1994 & 6 & 6 & 2 & 2 & 0 & 0 & 16 \\
\hline 1995 & 10 & 6 & 3 & 1 & 0 & 0 & 20 \\
\hline 1996 & 6 & 1 & 0 & 0 & 0 & 0 & 7 \\
\hline $\begin{array}{l}\text { Totals } \\
1967-1\end{array}$ & 42 & 108 & 46 & 8 & 2 & 0 & 206 \\
\hline Totals & 35 & 83 & 37 & 8 & 2 & 0 & 165 \\
\hline
\end{tabular}




\section{Appendix III. Frequency of Tornadoes within F-Scales (0 to 5) for the Georgia-South Carolina Region}

Frequency of tornadoes within F-Scales (0 to 5) for the Georgia-South Carolina region and for for two-degree square centered over the SRS. Totals for F-Scales 4 to 5 also include observations from Alabama (1951-1996).

\begin{tabular}{|c|c|c|}
\hline F-Scale & $\begin{array}{l}\therefore \quad \text { Georgia* } \\
\text { South Carolina* } \\
\end{array}$ & $\begin{array}{l}\text { Two-Degree Square } \\
\text { Centered Over the SRS }\end{array}$ \\
\hline$F(0)$ & 282 & 42 \\
\hline$F(1)$ & 730 & 108 \\
\hline $\mathrm{F}(2)$ & 323 & 46 \\
\hline$F(3)$ & 59 & 8 \\
\hline$F(4)$ & $34 *$ & $19^{*}$ \\
\hline$F(5)$ & $\because 6^{*}$ & $6^{*}$ \\
\hline
\end{tabular}

*Including Alabama 


\section{Appendix IV. Frequency of Occurrences for Tornadoes by 22.5 Degree Sector and F-Scale Classes}

Comparison of frequency of occurrences for tornadoes by 22.5 degree sector and F-scale classes. Each F-scale class is compared against the entire study area and the two-degree area centered on the SRS.
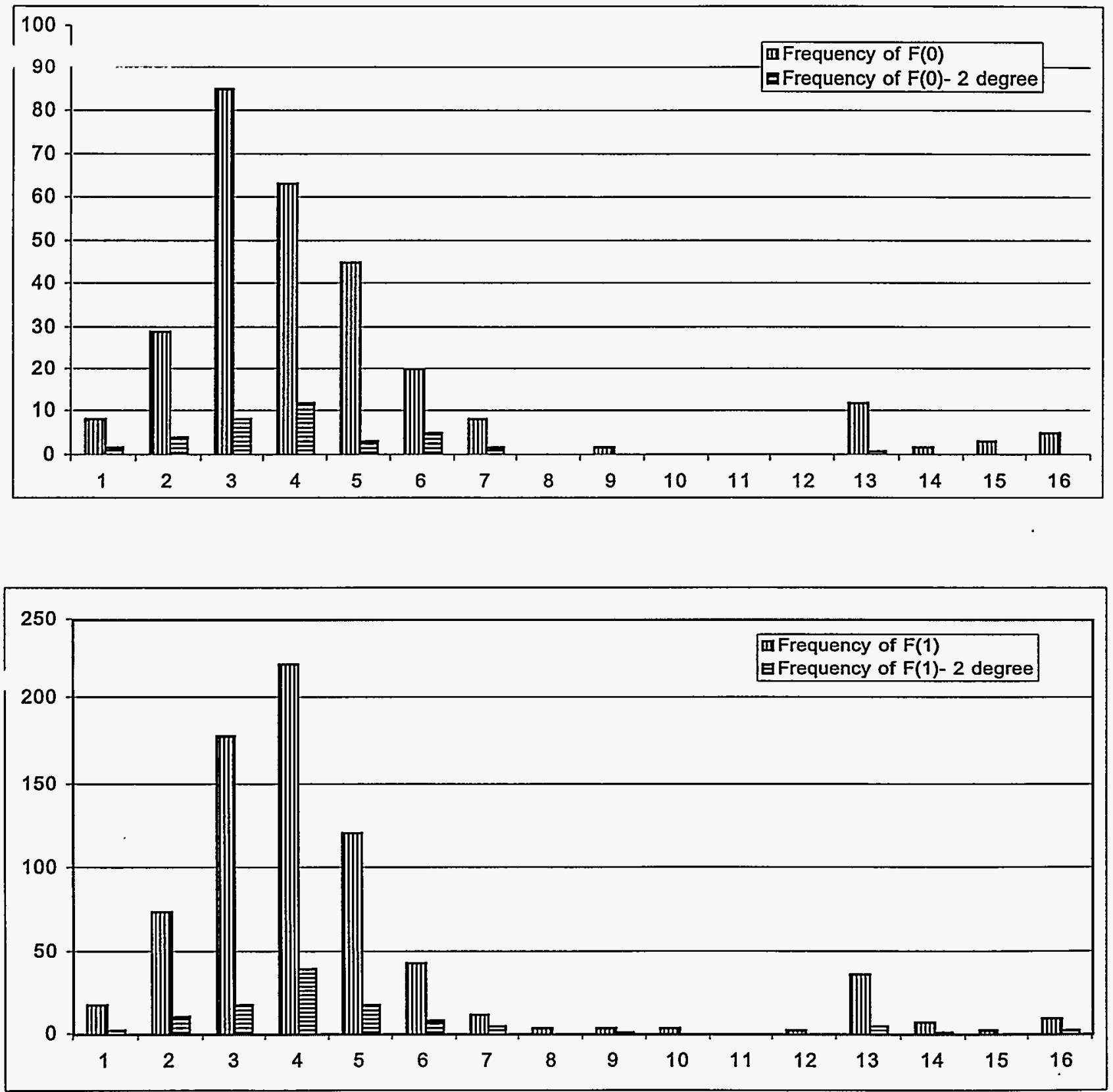


\section{Appendix IV. Frequency of Occurrences for Tornadoes by 22.5 Degree Sector and F-Scale Classes (contd)}
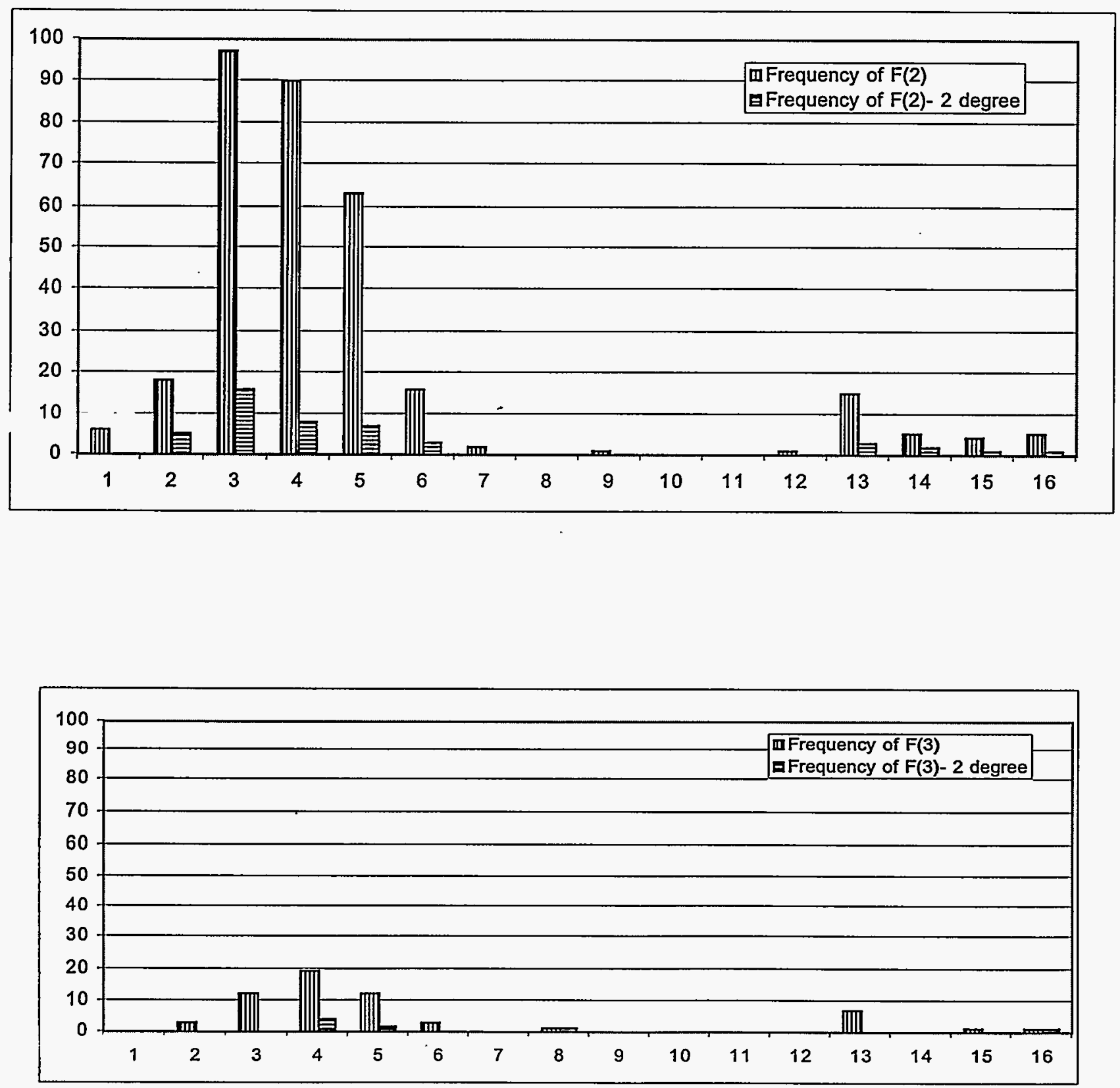


\section{Appendix IV. Frequency of Occurrences for Tornadoes by $\mathbf{2 2 . 5}$ Degree Sector and F-Scale Classes (contd)}
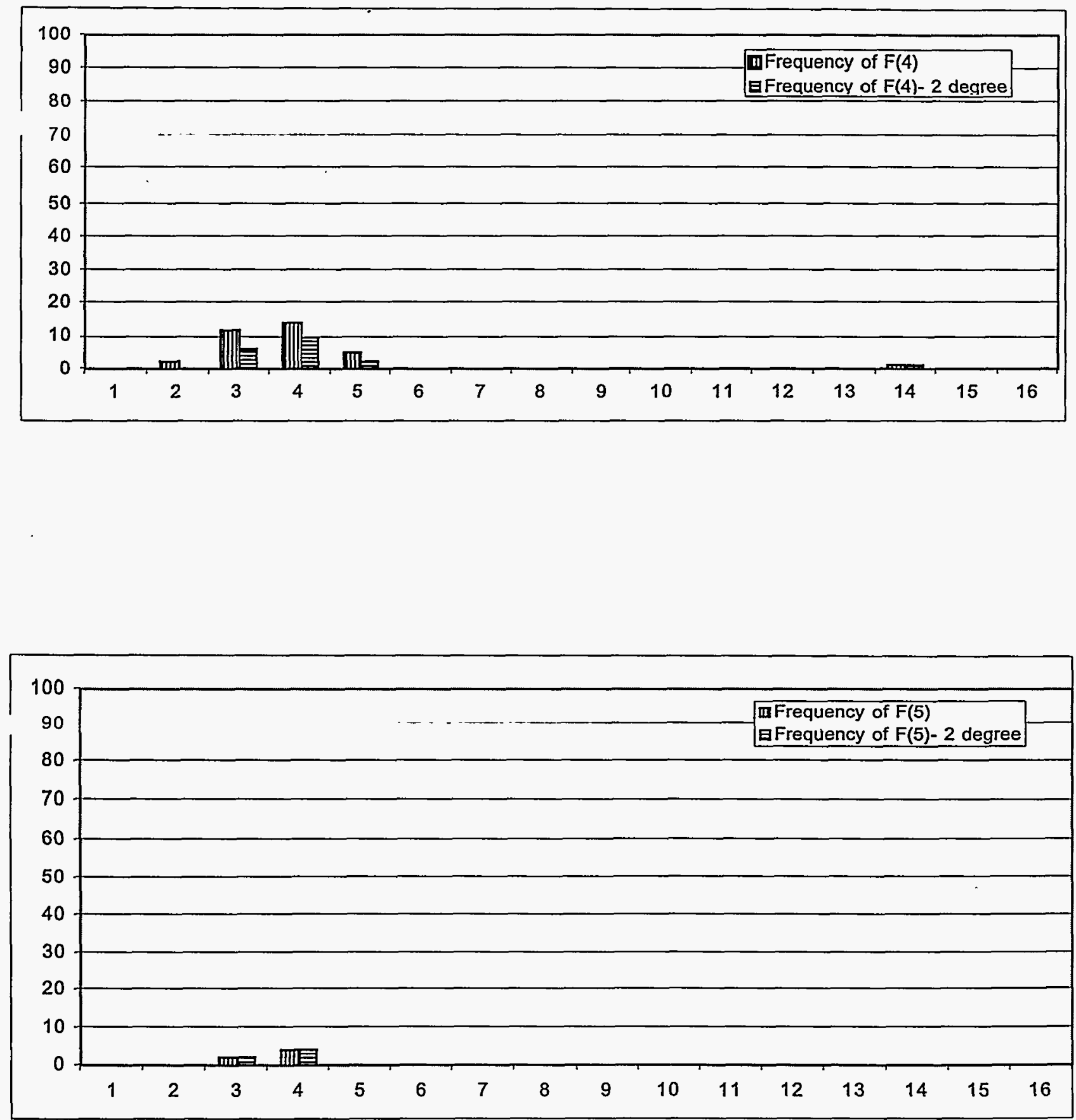


\section{Distribution List:}

R. P. Addis, 773-A, Rm.A-1011

C. H. Hunter, 773-A, Rm.A-1009

M. J. Parker, 773-A, RM.A-1005

C. O. Minyard, 773-A, Rm. A-1005

R. J. Kurzeja, 773-A, Rm. A-1020

A. H. Weber, 773-A, Rm. A-1012

K. Chen, 773-A, Rm. 1118

A. L. Boni, 773-A, Rm. A-202

P. T. Deason, 773-A, A-235

R. C. Tuckfeld, 773-42A

J. H. Weber, 773-42A

G. P. Shine, 773-42A

G. R. Peterson 703-F, Rm 57

D. C. Hanna, 703-46A

G. R. Whitney, 703A, B222

C. T. Edwards, 703-47A

J. L. Merrick, 703-47A

W. N. Kennedy, 730-1B/314

F. Loceff, 730-1B/319

G. B. Rawls, 730-1B/313

J. R. Joshi, 730-1B/3068

G. E. Mertz, 730-1B/3080

G. R. Baldwin, 730-1B/3081

J. P. Kelley, 730-1B/3070

L. A. Salomone, 730-2B/130

M. W. Lewis, 730-2B/116

M. E. Maryak, 730-2B/115

B. J. Gutierrez, 703-47A/220

D. P. Matthews, 706-8C

ETG files (15 copies) 